\title{
Depths of Large Earthquakes Determined From Long-Period Rayleigh Waves
}

\author{
JiAJUN ZHANG AND HIROO KANAMORI \\ Seismological Laboratory, California Institute of Technology, Pasadena
}

\begin{abstract}
The depths and source mechanisms of nine large shallow earthquakes were determined from long-period (150 to 300 s) Rayleigh waves recorded by the Global Digital Seismograph Network (GDSN) and International Deployment of Accelerometers (IDA) networks. We inverted the data set of complex source spectra for a moment tensor (linear) or a double couple (nonlinear). By solving a least squares problem, we obtained the centroid depth or the extent of the distributed source for each earthquake. The depths and source mechanisms of large shallow earthquakes determined from long-period Rayleigh waves depend on the models of source finiteness, wave propagation, and excitation. We tested various models of source finiteness, $Q$, group velocity, and excitation in the determination of earthquake depths. In order to determine the depth of large earthquakes from long-period surface waves, source-finiteness effects must be corrected using adequate models. The depth estimates obtained using the Q model of Dziewonski and Steim (1982) and the excitation functions computed for the average ocean model of Regan and Anderson (1984) are considered most reasonable. Dziewonski and Steim's Q model represents a good global average of Q determined over a period range of the Rayleigh waves used in this study. Since most of the earthquakes studied here occurred in subduction zones, Regan and Anderson's average ocean model is considered most appropriate. Our depth estimates are in general consistent with the Harvard centroid-moment tensor (CMT) solutions. The centroid depths and their $90 \%$ confidence intervals (numbers in parentheses) determined by the Student's $t$ test are Colombia-Ecuador earthquake (December 12, 1979), $d=11 \mathrm{~km}(9,24 \mathrm{~km})$; Santa Cruz Island earthquake (July 17, 1980), $d=36 \mathrm{~km}(18,46 \mathrm{~km})$; Samoa earthquake (September 1, 1981), $d=15 \mathrm{~km}(9,26 \mathrm{~km})$; Playa Azul, Mexico, earthquake (October 25, 1981), d = $41 \mathrm{~km}(28,49 \mathrm{~km}$ ); El Salvador earthquake (June $19,1982), \mathrm{d}=49 \mathrm{~km}(41,55 \mathrm{~km})$; New Ireland earthquake (March 18, 1983), d $=75 \mathrm{~km}(72,79 \mathrm{~km})$; Chagos Bank earthquake (November 30, 1983), $d=31 \mathrm{~km}(16,41 \mathrm{~km})$; Valparaiso, Chile, earthquake (March 3, 1985), $d=44 \mathrm{~km}(15,54 \mathrm{~km})$; Michoacan, Mexico, earthquake (September 19, 1985), $d=24 \mathrm{~km}$ $(12,34 \mathrm{~km})$.
\end{abstract}

\section{INTRODUCTION}

Investigation of the depth extent of faulting of large earthquakes is important for a better understanding of the state of stress and the mechanical properties of fault zones. Large shallow thrust earthquakes usually occur on the interface between the subducting oceanic lithosphere and the overriding continental or island-arc lithosphere, and are due to relative plate motion. The earthquakes which occurred seaward of, or beneath, the trench within the oceanic plate are mainly normalfault events and are interpreted as the results of bending or arching of the oceanic plate or the slab pulling. The tearing of the lithosphere is also considered as the cause of some shallow earthquakes. The distribution and mechanism of earthquakes near midocean ridges may indicate that the thermal contraction resulted from cooling of the hot material moving away from the ridge is an important source of stress in young lithospheres [Wiens and Stein, 1983, 1984; Bergman and Solomon, 1984].

The depth and other source parameters of earthquakes have been traditionally determined from the arrivals of the earliest waves, which have a common origin at a point in the source region. Another approach to estimate these parameters is to use the waveforms or spectra of body waves, surface waves, or free oscillations of the earth excited by the earthquake. For large earthquakes the results obtained from the second approach are not related to the motion of a point in the source region at any moment, but are spatially and temporally averaged quantities about the source of the earthquake. In this approach, the centroid location and time, which represent in some sense the

Copyright 1988 by the American Geophysical Union.

Paper number 7B6075

0148-0227/88/007B-6075\$05.00 best location and time of an equivalent point source, are determined [Backus and Mulcahy, 1976; Dziewonski et al., 1981; Dziewonski and Woodhouse, 1983].

Many studies have focused on the determination of source parameters from long-period surface wave or free oscillation data [Aki, 1960a, b; Kanamori, 1970; Gilbert and Dziewonski, 1975; Dziewonski et al., 1981; Kanamori and Given, 1981; Silver and Jordan, 1983]. For very large earthquakes, the centroid depth from long-period data may not coincide with that from shorter-period, body wave observations. Romanowicz and Guillemant [1984] proposed a method to retrieve the centroid depth and the moment tensor of large earthquakes using spectra of long-period Rayleigh waves. The determination of the centroid depth involves a nonlinear inverse problem.

There are several difficulties preventing accurate depth determination using long-period surface waves. First, large shallow earthquakes have large rupture extents and long duration. Their lateral rupture extent is often comparable to, or larger than, the vertical extent. The source process of large earthquakes is in general complex because asperities in the fault zone cause complexities in the spatial and temporal variation of the dislocation along the fault plane. Second, the differences in the lithosphere structure between different regions may not be negligible in the excitation of these waves. Third, the corrections for the propagation effects on the amplitudes and phases of waves are often very large.

Recent progress in the studies of source finiteness [Romanowicz and Monfret, 1986; Zhang and Kanamori, 1988] and the lateral heterogeneity of the earth [Nakanishi and Anderson, 1983, 1984; Woodhouse and Dziewonski, 1984; Tanimoto, 1985,1986 ] made possible a direct use of surface wave data in the determination of the depth extent of large earthquakes. Various global average or laterally heterogeneous models for 
phase velocity, group velocity, $Q$, and surface wave excitation or free oscillation of the earth have been developed [e.g., Kanamori, 1970; Dziewonski and Anderson, 1981; Dziewonski and Steim, 1982; Anderson and Given, 1982; Nakanishi and Anderson, 1984; Regan and Anderson, 1984]. An examination of the effects of the choice of different earth models on the determination of the depth and other source parameters is necessary.

In this paper, we made a detailed study in the depth determination of large shallow earthquakes using various models for excitation and propagation of surface waves. We first describe the method to retrieve the depth and the mechanism of a moment tensor or double couple source, which is similar to the method of Romanowicz and Guillemant [1984]. We determined the source depth and mechanism of nine earthquakes from long-period Rayleigh waves recorded by the Global Digital Seismograph Network (GDSN) and International Deployment of Accelerometers (IDA) networks.

\section{Method}

\subsection{Moment Tensor Inversion}

We use the notation of Kanamori and Given [1981]. The source spectrum of surface waves excited by a step-function point source is a linear function of a frequency-independent moment tensor $\left(M_{x x}, M_{y y}, M_{z z}, M_{x y}, M_{y z}, M_{x z}\right)$. We write the source spectrum as

$$
\hat{V}(\omega, h, \phi)=\alpha(\omega, h, \phi)+i \beta(\omega, h, \phi)
$$

For a deviatoric moment tensor, the real $(\alpha)$ and imaginary ( $\beta$ ) parts of the spectrum are

$$
\begin{aligned}
& \alpha=-P_{R}^{(1)}(\omega, h) M_{x y} \sin 2 \phi+\frac{1}{2} P_{R}^{(1)}(\omega, h)\left(M_{y y}-M_{x x}\right) \cos 2 \phi \\
& -\frac{1}{2} S_{R}^{(1)}(\omega, h)\left(M_{y y}+M_{x x}\right) \\
& \beta=Q_{R}^{(1)}(\omega, h) M_{y z} \sin \phi+Q_{R}^{(1)}(\omega, h) M_{x z} \cos \phi
\end{aligned}
$$

for the vertical component of Rayleigh waves, and

$$
\begin{aligned}
\alpha=- & \frac{1}{2} P_{L}^{(1)}(\omega, h)\left(M_{y y}-M_{x x}\right) \sin 2 \phi \\
& \quad-P_{L}^{(1)}(\omega, h) M_{x y} \cos 2 \phi \\
\beta=- & Q_{L}^{(1)}(\omega, h) M_{x z} \sin \phi+Q_{L}^{(1)}(\omega, h) M_{y z} \cos \phi
\end{aligned}
$$

for the transverse component of Love waves. Here $\omega$ is the angular frequency, and $P_{R}^{(1)}, S_{R}^{(1)}, Q_{R}^{(1)}, P_{L}^{(1)}$, and $Q_{L}^{(1)}$ are the excitation functions given by Kanamori and Stewart [1976], which depend on the elastic properties in the source region and the source depth $(h)$.

The spectrum $\hat{V}(\omega, h, \phi)$ can be calculated from the spectrum of the surface wave seismogram $\hat{U}_{r}(\vec{r}, \omega)$ corrected for instrument response, propagation, and source finiteness.

Romanowicz and Guillemant [1984] proposed a two-step inversion procedure to solve the system of equations (2). The first step inversion solves the following system:

$$
B D=V
$$

where

$$
B=\left[\begin{array}{ccccc}
-\sin 2 \phi_{1} & \frac{1}{2} \cos 2 \phi_{1} & -\frac{1}{2} & 0 & 0 \\
0 & 0 & 0 & \sin \phi_{1} & \cos \phi_{1} \\
-\sin 2 \phi_{2} & \frac{1}{2} \cos 2 \phi_{2} & -\frac{1}{2} & 0 & 0 \\
0 & 0 & 0 & \sin \phi_{2} & \cos \phi_{2} \\
\cdot & \cdot & \cdot & . & \cdot \\
\cdot & \cdot & \cdot & \cdot & \cdot \\
\cdot & \cdot & \cdot & \cdot & \cdot \\
-\sin 2 \phi_{N} & \frac{1}{2} \cos 2 \phi_{N} & -\frac{1}{2} & 0 & 0 \\
0 & 0 & 0 & \sin \phi_{N} & \cos \phi_{N}
\end{array}\right]
$$

and

$$
\begin{aligned}
D= & {\left[P_{R}^{(1)}(\omega, h) M_{x y}, P_{R}^{(1)}(\omega, h)\left(M_{y y}-M_{x x}\right),\right.} \\
& \left.S_{R}^{(1)}(\omega, h)\left(M_{y y}+M_{x x}\right), Q_{R}^{(1)}(\omega, h) M_{y z}, Q_{R}^{(1)}(\omega, h) M_{x z}\right]^{T}
\end{aligned}
$$

and

$$
\begin{aligned}
V=\left[\alpha\left(\omega, h, \phi_{1}\right), \beta\left(\omega, h, \phi_{1}\right),\right. & \cdots \\
& \left.\alpha\left(\omega, h, \phi_{N}\right), \beta\left(\omega, h, \phi_{N}\right)\right]^{T}
\end{aligned}
$$

where $\mathrm{N}$ is the number of records obtained from stations with azimuths $\phi_{1}, \cdots, \phi_{N}$ from the source. $B$ is an $2 \mathrm{~N} \times 5$ real matrix, and $V$ is a real vector with dimension $2 \mathrm{~N}$. The system (4) is solved for $D(\omega)$ using the data vector $V(\omega)$ at several frequencies: $\omega_{1}, \omega_{2}, \cdots, \omega_{K}$.

In the second step, the moment tensor is determined from the vectors $D\left(\omega_{i}\right),(i=1, \ldots, K)$ for given excitation functions. The moment tensor can be obtained by solving the following system:

$$
\Gamma M=\Lambda
$$

where

$$
\begin{gathered}
\Gamma=\left[\Gamma_{1}, \Gamma_{2}, \ldots, \Gamma_{K}\right]^{T} \\
\Gamma_{i}=\operatorname{diag}\left[P_{R}^{(1)}\left(\omega_{i}, h\right), P_{R}^{(1)}\left(\omega_{i}, h\right), S_{R}^{(1)}\left(\omega_{i}, h\right),\right. \\
\left.Q_{R}^{(1)}\left(\omega_{i}, h\right), Q_{R}^{(1)}\left(\omega_{i}, h\right)\right] \quad(i=1, \ldots, K) \\
M=\left[M_{x y},\left(M_{y y}-M_{x x}\right),\left(M_{y y}+M_{x x}\right), M_{y z}, M_{x z}\right]^{T}
\end{gathered}
$$

and

$$
\Lambda=\left[D^{T}\left(\omega_{1}\right), D^{T}\left(\omega_{2}\right), \ldots, D^{T}\left(\omega_{K}\right)\right]^{T}
$$

The minimum sum of squares of the least squares (LS) problem in the second step can be written as

$$
\rho_{L S}^{2}=\left\|\left(I-\Gamma\left(\Gamma^{T} \Gamma\right)^{-1} \Gamma^{T}\right) \Lambda\right\|^{2}
$$

For each trial source depth, we calculate the error, $\rho_{L S} / \sqrt{5 K}$, the root-mean-square ( $R M S)$ of the residuals of the inversion. Since the excitation function depends on the depth, the error is a function of the depth. We invert (5) for the moment tensor and find the depth that minimizes the error. However, if only 
one frequency is considered $(K=1)$, the error vanishes for any given trial depth, since $\Gamma$ becomes diagonal and (5) is solved exactly.

\subsection{Fault Inversion}

The method of Romanowicz and Guillemant [1984] can be extended to estimate the source parameters and depth of a double couple source. If the source is a double couple, (2) and (3) are replaced by

$$
\begin{gathered}
\alpha=P_{R}^{(1)}(\omega, h) M_{o} p_{R}+S_{R}^{(1)}(\omega, h) M_{o} s_{R} \\
\beta=Q_{R}^{(1)}(\omega, h) M_{o} q_{R}
\end{gathered}
$$

and

$$
\begin{aligned}
& \alpha=P_{L}^{(1)}(\omega, h) M_{o} p_{L} \\
& \beta=Q_{L}^{(1)}(\omega, h) M_{o} q_{L}
\end{aligned}
$$

respectively, where $M_{0}$ is the scalar seismic moment, $s_{R}, p_{R}$, $q_{R}, p_{L}$, and $q_{L}$ are determined from the fault parameters, dip angle $\delta$, slip angle $\lambda_{s}$ and strike $\phi_{f}$ defined by Ben-Menahem et al. [1965] (also see Kanamori and Stewart [1976]).

For Rayleigh waves, the system (4) is solved in the first step for $D(\omega)$ at various frequencies. Here the matrix $\mathrm{B}$ remains the same as in (4), while the vector $D(\omega)$ is replaced by

$$
\begin{aligned}
D=\left[P_{R}^{(1)}(\omega, h) m_{1},\right. & P_{R}^{(1)}(\omega, h) m_{2}, S_{R}^{(1)}(\omega, h) m_{3}, \\
& \left.Q_{R}^{(1)}(\omega, h) m_{4}, Q_{R}^{(1)}(\omega, h) m_{5}\right]^{T}
\end{aligned}
$$

where

$$
\begin{aligned}
& m_{1}=M_{o}\left(-\cos \lambda \sin \delta \cos 2 \phi_{f}-\sin \lambda \sin \delta \cos \delta \sin 2 \phi_{f}\right) \\
& m_{2}=M_{o}\left(2 \cos \lambda \sin \delta \sin 2 \phi_{f}-2 \sin \lambda \sin \delta \cos \delta \cos 2 \phi_{f}\right) ; \\
& m_{3}=M_{o}(-2 \sin \lambda \sin \delta \cos \delta) ; \\
& m_{4}=M_{o}\left(-\cos \lambda \cos \delta \sin \phi_{f}+\sin \lambda \cos 2 \delta \cos \phi_{f}\right) \\
& m_{5}=M_{o}\left(\sin \lambda \cos 2 \delta \sin \phi_{f}+\cos \lambda \cos \delta \cos \phi_{f}\right)
\end{aligned}
$$

Note $m_{i} \quad(i=1, \ldots, 5)$ can be written as $m_{1}=M_{x y}$, $m_{2}=M_{y y}-M_{x x}, \quad m_{3}=M_{y y}+M_{x x}, \quad m_{4}=M_{y z}, \quad$ and $m_{5}=M_{x z}$, where $M_{x x x}, M_{y y}, M_{x y}, M_{x z}$, and $M_{y z}$ are components of the moment tensor corresponding to the double couple.

In the second step, a system in the form of (5) is solved for $M_{o}, \delta, \lambda$, and $\phi_{f}$ using the vector $\Gamma$. Here $\Gamma_{i}(i=1, \ldots, K)$ remain the same as in (5), while the vector $M$ is replaced by $M=\left(m_{1}, m_{2}, m_{3}, m_{4}, m_{5}\right)$, where the $m_{i}$ are the nonlinear functions of $\delta, \lambda$, and $\phi_{f}$, defined above.

For a given depth, we solve the nonlinear system for $M_{o}, \delta$, $\lambda$, and $\phi_{f}$ and calculate the error, $\rho_{L S} / \sqrt{5 K}$. We find the depth of the double couple source which minimizes the error.

The methods for the depth determination from Love waves and from both Rayleigh and Love waves are given in the appendix.

\section{EARTh Model}

The determination of the depth extent of earthquakes from surface waves requires an accurate description of excitation characteristics and propagation effects.

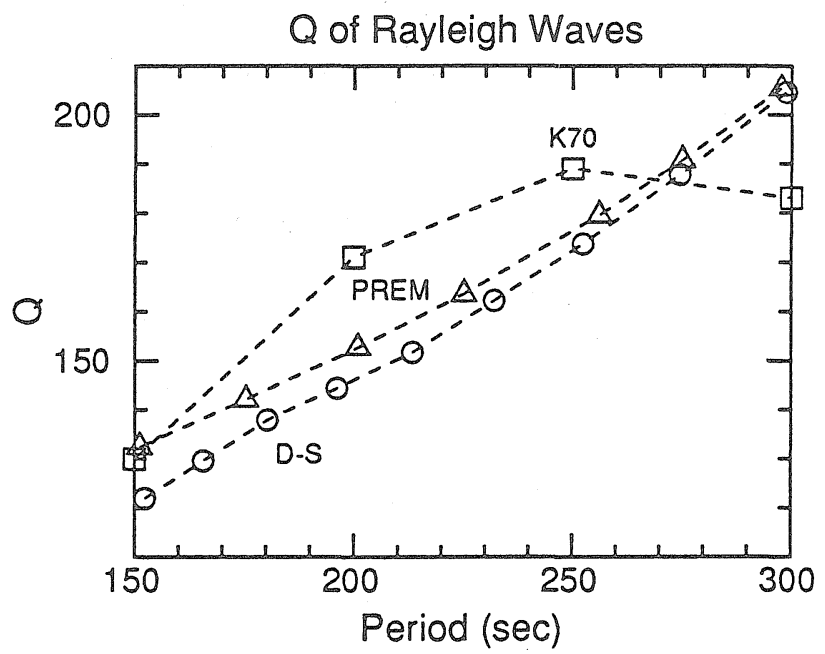

Fig. 1. Comparison of three models of attenuation for Rayleigh waves: the model of Kanamori [1970] (squares), the PREM model (triangles), and the model of Dziewonski and Steim [1982] (circles).

\subsection{Phase Velocity and $Q$}

Recently several laterally heterogeneous earth models of phase velocities have been proposed [Nakanishi and Anderson, 1983, 1984; Woodhouse and Dziewonski, 1984; Tanimoto, $1985,1986]$. In this study, the phase shifts of surface waves due to propagation are corrected using the laterally heterogeneous earth model M84C obtained by Woodhouse and Dziewonski [1984]. Romanowicz and Monfret [1986] used several models of phase velocity to correct for the observed phase delays due to propagation. Their results indicate that the choice of the phase velocity model is not critical to the estimates of the depth and source parameters.

The propagation effects on the amplitude are corrected with models of group velocity and $\mathbf{Q}$. In the period range concerned, the global average of the group velocity of mantle Rayleigh waves is probably good to better than $1 \%$ [Mills and Hales, 1977, 1978; Mills, 1978; Fukao and Kobayashi, 1983; Dziewonski and Steim, 1982; Nakanishi and Anderson, 1984]. In the following, we use three different models, which are the model of Kanamori [1970], PREM [Dziewonski and Anderson, 1981], and the model of Nakanishi and Anderson [1984].

In contrast with the similarities between the group velocity data given by different investigators, the published data on attenuation of surface waves or normal modes often differ by more than $5 \%$ in the period range from 150 to $300 \mathrm{~s}$. Figure 1 shows the $Q$ values in the period range for three models, the model of Kanamori [1970], PREM, and the model of Dziewonski and Steim [1982]. In the period range concerned, the last model is consistent with the data set compiled by Anderson and Given [1982] from Anderson and Hart [1978a, b], Chael and Anderson [1982], Nakanishi [1979], and Dziewonski and Steim [1982]. We determined the depths of earthquakes using three models of the group velocity and $Q$. The first model is the model of Kanamori [1970] (hereinafter referred to as $\mathbb{K} 70$ ). The second model is PREM. The third model uses the $Q$ given by Dziewonski and Steim [1982] and group velocities by Nakanishi and Anderson [1984]. Later we will refer to the last model as D-S. Since these models differ principally in $\mathbb{Q}$ rather than in the group velocity, we will call them $Q$ models. 


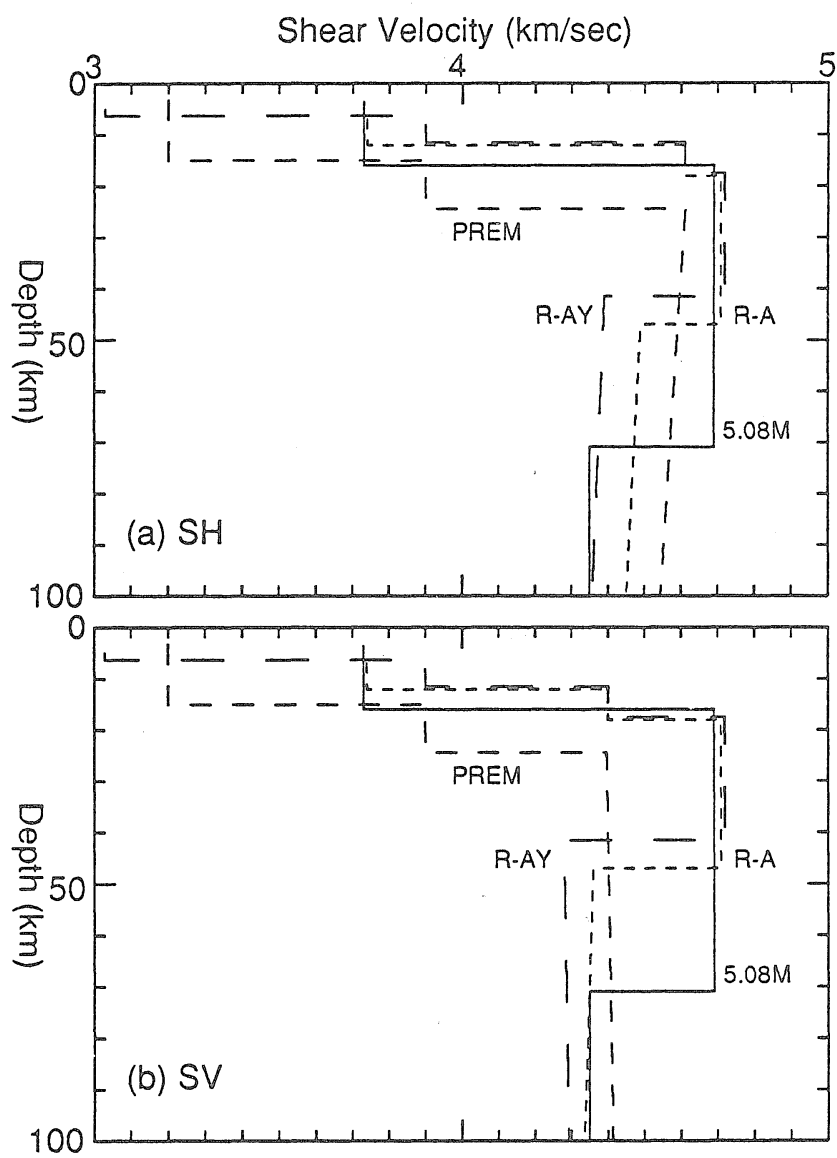

Fig. 2. Shear velocities at a reference period of $1 \mathrm{~s}$ in the uppermost $100 \mathrm{~km}$ for the models of 5.08M [Press, 1970; Kanamori, 1970], PREM [Dziewonski and Anderson, 1981], the average ocean (R-A), and 20 $50 \mathrm{Ma}$ ocean (R-AY) of Regan and Anderson [1984]. (a) Horizontal and (b) vertical components of shear velocities are shown for layers of anisotropic structure.

\subsection{Excitation}

As seen from (5), the wave excitation is directly related to the determination of source parameters. We investigated the effect of different choices of the earth model on the depth estimates. We used four spherically symmetric earth models:

1. 5.08M [Press, 1970; Kanamori, 1970]. This model is the simplest considered here, in which the lithosphere (Lid) spans a depth range from $16 \mathrm{~km}$, the depth of the Moho, to $71 \mathrm{~km}$, the top of the low-velocity zone (LVZ), where the shear wave velocity drops by $7 \%$.

2. PREM [Dziewonski and Anderson, 1981].

3. The average oceanic model $\mathbf{A}$ of Regan and Anderson [1984] (hereinafter referred to as $\mathbb{R}-\mathbf{A}$ ). This model has a $\mathrm{Lid}$ from 12 to $47 \mathrm{~km}$, the top of the $L V Z$, where the velocity discontinuity is about $7 \%$.

4. The model for the ocean of $20-50 \mathrm{Ma}$ in age of the ocean floor of Regan and Anderson [1984] (hereinafter referred to as $\mathbb{R}-\mathbf{A Y}$ ). This model is close to $\mathbb{R}-\mathbf{A}$ except that the $\mathrm{Lid}$ is thinner and the velocity in the crust is higher.

Figures $2 \mathrm{a}$ and $2 \mathrm{~b}$ show the shear velocity at a reference period of $1 \mathrm{~s}$ in the upper $100 \mathrm{~km}$ for these earth models. PREM, R-A, and R-AY are anisotropic. In PREM there is no Lid at the period of $1 \mathrm{~s}$, and the bottom of the Lid is at $80-\mathrm{km}$ depth at the period of $200 \mathrm{~s}$. In these anisotropic models, at a reference period of $200 \mathrm{~s}$, the velocity above the $\mathrm{LVZ}$ in each model remains about the same as that at $1 \mathrm{~s}$, while in the $\mathrm{LVZ}$ it drops by about $2 \%$ from the velocity at $1 \mathrm{~s}$. A very pronounced high-velocity $\mathbb{L i d}$ is a prominent feature of $5.08 \mathrm{M}, \mathbb{R}$ $A$, and R-AY compared with PREM. For each earth model, we computed the source excitations and used them for the depth determination.

\section{SOURCE FintTENESS}

Because of the long duration and the large spatial extent of the earthquakes studied here, the source phase and amplitude spectra for the period range considered differ considerably from the spectra of a point source with a step time function. The method to measure the magnitude of source-finiteness effects on the spectra of long-period surface waves and the observability of the source finiteness is described by Zhang and Kanamori [1988] (hereinafter referred to as ZKK). We use their notation in the following. The observability of the source finiteness is measured by $\eta(\omega)=\bar{V}(\omega) \bar{S}(\omega) / \varepsilon(\omega)$, where $\bar{V}(\omega)$ is the amplitude spectrum averaged over all stations, $\bar{S}(\omega)$ is the magnitude of the spectral variation due to the source finiteness, and $\varepsilon(\omega)$ is a measure of the noise given by the error in the inversion. For the 1979 Colombia-Ecuador earthquake, $\bar{S}$ is greater than 1 for the period range of 150 to $300 \mathrm{~s}$, indicating that the deviation from the point-source spectra is significant.

Several simple models have been used to represent the source of large earthquakes. The first model is a point source with a step time function. The second model is a point source with a step time function with a delay time, which is determined from the phase spectra. The delay time may be considered as the half source duration. This model is used by Romanowicz and Monfret [1986]. The phase spectra are corrected for the source-finiteness effects before the inversion. The third is a point source with finite source duration. The last is a finite-fault or propagating source. For the last two models, both the amplitude and phase spectra are corrected before the inversion. $\mathbb{Z K}$ used a finite-fault model to study the source directivity of large earthquakes. The model parameters are the rupture length, the rupture azimuth, the rupture velocity, and the rise time.

For a unilateral fault with rupture velocity $V$, length $L$, and dislocation time $\tau$, the overall source duration is given as

$$
\tau_{s}=\frac{L}{V}+\tau
$$

For a bilateral faulting, the source duration can be obtained in the same way, with $L$ replaced by the length of the larger segment. The source-finiteness effect for a point source with finite duration is given by

$$
\frac{\sin \left(\omega t_{f} / 2\right)}{\left(\omega \tau_{f} / 2\right)} \frac{\sin (\omega \tau / 2)}{(\omega \tau / 2)} \exp \left(-i \omega t_{s} / 2\right)
$$

where $t_{f}=\mathbb{L} / \mathbb{V}$ is the rupture duration or the rupture time.

For a point source with a delay time $\tau_{d}$, the source-finiteness effect is given by

$$
\exp \left(-i \omega \tau_{d}\right)
$$

The source finiteness causes phase delay. Ben-Menahem [1961] introduced the directivity function and showed that radiation of waves is strongly diminished at the periods close to the rupture time. In general the source finiteness diminishes the amplitude of short-period waves. Shallow earthquakes have 
TABLE 1. Epicentral Data for Events Used in This Study

\begin{tabular}{clrrrrr}
\hline Event & \multicolumn{1}{c}{ Location } & Date & UTC & Latitude & Longitude & $\mathrm{M}_{s}$ \\
\hline 1 & Colombia-Ecuador & Dec. 12, 1979 & $0759: 03.3$ & $1.598^{\circ} \mathrm{N}$ & $79.358^{\circ} \mathrm{W}$ & 7.7 \\
2 & Santa Cruz Island & July 17, 1980 & $1942: 23.2$ & $12.525^{\circ} \mathrm{S}$ & $165.916^{\circ} \mathrm{E}$ & 7.9 \\
3 & Samoa & Sept. 1, 1981 & $0929: 31.5$ & $14.960^{\circ} \mathrm{S}$ & $173.085^{\circ} \mathrm{W}$ & 7.7 \\
4 & Playa Azul, Mexico & Oct. 25, 1981 & $0322: 15.5$ & $18.048^{\circ} \mathrm{N}$ & $102.084^{\circ} \mathrm{W}$ & 7.3 \\
5 & El Salvador & June 19, 1982 & $0621: 58.0$ & $13.313^{\circ} \mathrm{N}$ & $89.339^{\circ} \mathrm{W}$ & 7.0 \\
6 & New Ireland & March 18, 1983 & $0905: 50.0$ & $4.884^{\circ} \mathrm{S}$ & $153.581^{\circ} \mathrm{E}$ & 7.6 \\
7 & Chagos Bank & Nov. 30, 1983 & $1746: 00.6$ & $6.852^{\circ} \mathrm{S}$ & $72.110^{\circ} \mathrm{E}$ & 7.7 \\
8 & Valparaiso, Chile & March 3, 1985 & $2247: 07.3$ & $33.135^{\circ} \mathrm{S}$ & $71.871^{\circ} \mathrm{W}$ & 7.8 \\
9 & Michoacan, Mexico & Sept. 19, 1985 & $1317: 47.3$ & $18.190^{\circ} \mathrm{N}$ & $102.533^{\circ} \mathrm{W}$ & 8.1 \\
\hline
\end{tabular}

relatively more short-period energy than deep earthquakes for the fundamental surface waves in the period range concerned. Therefore the inversion of the spectra which are not corrected for the phase delay or the amplitude effects due to the source finiteness tends to place the centroid at a depth greater than the true depth. In order to determine the depth of large earthquakes from long-period surface waves, source-finiteness effects must be corrected using adequate models.

The finite-fault models of the earthquakes studied here are determined using the method of $\mathrm{ZK}$ with the propagation phase delay corrected for using the model $\mathrm{M} 84 \mathrm{C}$ and the attenuation corrected for using $\mathrm{K} 70$. $\mathrm{ZK}$ show that the average of the differences between the source duration estimated with the model M84C and with a homogeneous model [Gilbert and Dziewonski, 1975] is around $10 \mathrm{~s}$ for large earthquakes. The differences between the estimates of the source duration for various earth models of $\mathrm{Q}$ are very small.

For the 1979 Colombia-Ecuador, the 1985 Valparaiso, Chile, and the 1985 Michoacan, Mexico, earthquakes the finite-fault models of the earthquakes determined by $\mathrm{ZK}$ are used in this study. For other earthquakes studied here, we first computed $\eta(\omega)$ at various periods from 150 to $300 \mathrm{~s}$, which measures the observability of the source finiteness at a given period. Except for the 1981 Samoa earthquake, all other earthquakes have largest $\eta(\omega)$ at $256 \mathrm{~s}$. Therefore we used the data set of 256-s period to obtain the finite-fault models of these earthquakes. In determining the source-finiteness models of these earthquakes, we used the spectra with the amplitudes corrected for the propagation effects using a spherically symmetric model of $Q$ and the group velocity $\mathbb{K} 70$.

For earthquakes of relatively small size, such as the $1982 \mathrm{El}$ Salvador and 1981 Playa Azul, Mexico, earthquake, the determination of the source directivity is difficult. The finite-fault models of these earthquakes cannot be determined well. However, for these relatively small earthquakes, the difference between the depth obtained using a point source model with finite duration and that using the finite-fault model is very small (less than $5 \mathrm{~km}$ ). In the following, we estimate the depth of large earthquakes using the finite-fault model, although the source directivity of some earthquakes cannot be determined with confidence.

\section{DAtA}

Table 1 lists the hypocentral parameters of nine large earthquakes studied here determined by the National Earthquake Information Center (NEIC). The basic data are spectra at periods from 150 to $300 \mathrm{~s}$ computed from the vertical component Rayleigh waves ( $R_{2}$ and $R_{3}$ phases). The periods used are $150,175,200,225,256,275$, and $300 \mathrm{~s}$. The propagation corrections in the phase are made with the laterally heterogene- ous earth model (M84C) obtained by Woodhouse and Dziewonski [1984].

\section{Depth Determination}

We determined the source depth of the nine large earthquakes from the spectra of long-period Rayleigh waves using the methods described above. We inverted the spectra corrected for the source finiteness for a moment tensor or a double couple to determine the depth which minimizes the error in the inversion.

We used various $Q$ models and excitation functions discussed above. For the purpose of illustrating the method, we used the simplest combination, $K 70 Q$ model and excitation functions computed for model $5.08 \mathrm{M}$. This combination is denoted by $(\mathrm{K} 70,5.08 \mathrm{M})$. In order to see the effect of $\mathrm{Q}$ model and excitation functions on depth, we tried different combinations which are denoted in a similar fashion.

Tables 2 and 3 summarize the results obtained with the combination of the D-S Q model and R-A earth model, we consider most appropriate for our purpose. In the following, we discuss the results for the individual events in detail. The ColombiaEcuador earthquake has the largest seismic moment among the events studied. We describe the procedure for the determination of the depth for this event. For other earthquakes we focus our discussion on specific features of each event.

\subsection{Colombia-Ecuador Earthquake}

The December 12, 1979, earthquake occurred near the coast of Ecuador and caused extensive damage in the Pasto-TumacoBuenaventura area and on Gergona Island, Colombia. The earthquake was located about $80 \mathrm{~km}$ landward from the Colombia trench. It is a very large thrust event which occurred at the boundary between the subducting Nazca plate and the overriding South America plate. The earthquake caused large tsunamis $3 \mathrm{~m}$ (peak-to-trough) high along the Colombia coast and extensive subsidence up to $1.6 \mathrm{~m}$ along a $200-\mathrm{km}$-long segment along the coast [Herd et al., 1981]. This indicates that the depth of the earthquake is shallow.

The aftershocks of the earthquake are distributed from the depth of a few kilometers to about $35 \mathrm{~km}$ [Mendoza and Dewey, 1984]. The hypocenter of the main shock was determined at the depth of $29 \mathrm{~km}$ by the International Seismological Centre (ISC), and $24 \mathrm{~km}$ by the NEIC. Mendoza and Dewey [1984] pointed out that the depth phases in the complex P wave trains of the earthquake cannot be identified with confidence, but the data from regional stations permitted the determination of the focal depth of $37.5 \mathrm{~km}$ with a precision of about $19 \mathrm{~km}$ using only $\mathrm{P}$ wave arrival time data.

The Harvard centroid-moment tensor (CMT) solution of the earthquake has a depth of $20 \mathrm{~km}$ [Giardini et al., 1985]. Romanowicz and Guillemant [1984] estimated the centroid 
TABLE 2. Results by Moment Tensor Inversion With (D-S, R-A)

\begin{tabular}{|c|c|c|c|c|c|c|c|c|c|c|c|c|c|c|c|}
\hline \multirow{2}{*}{ Event } & \multirow{2}{*}{ Location } & \multirow{2}{*}{$\begin{array}{c}\text { Depth, } \\
\text { km } \\
\end{array}$} & \multirow{2}{*}{$M_{x y}$} & \multirow{2}{*}{$\mathrm{M}_{\mathrm{yy}}-\mathrm{M}_{\mathrm{xx}}$} & \multirow{2}{*}{$\mathrm{M}_{\mathrm{yy}}+\mathrm{M}_{\mathrm{xx}}$} & \multirow{2}{*}{$\mathrm{M}_{\mathrm{yz}}$} & \multirow{2}{*}{$M_{x z}$} & \multicolumn{7}{|c|}{ Major Double Couple } & \multirow{2}{*}{$\begin{array}{c}\mathrm{m}_{\mathrm{o}} / \mathrm{M}_{\mathrm{o}} \\
\% \\
\end{array}$} \\
\hline & & & & & & & & $\mathrm{M}_{0}$ & $\delta_{1}$ & $\lambda_{1}$ & $\phi_{1}$ & $\delta_{2}$ & $\lambda_{2}$ & $\phi_{2}$ & \\
\hline 1 & Colombia-Ecuador & 11 & - & $\begin{array}{l}- \\
-\end{array}$ & - & $\begin{array}{l}- \\
-\end{array}$ & $\begin{array}{l}- \\
-\end{array}$ & 21.4 & 15.0 & 60.0 & 358.0 & 77.5 & 97.6 & 208.8 & - \\
\hline 2 & Santa Cruz Island & 36 & $\begin{array}{r}1.5 \\
\pm 0.2\end{array}$ & $\begin{array}{l}-5.8 \\
\pm 0.3\end{array}$ & $\begin{array}{l}-5.5 \\
\pm 0.2\end{array}$ & $\begin{array}{r}3.3 \\
\pm 0.3\end{array}$ & $\begin{array}{r}0.2 \\
\pm 0.3\end{array}$ & 6.8 & 31.6 & 73.1 & 336.0 & 59.9 & 100.1 & 175.6 & 6 \\
\hline 3 & Samoa & 15 & $\begin{array}{l}-0.78 \\
\pm 0.1\end{array}$ & $\begin{array}{l}-2.26 \\
\pm 0.2\end{array}$ & $\begin{array}{c}1.61 \\
\pm 0.1\end{array}$ & $\begin{array}{l}-0.01 \\
\pm 1.3\end{array}$ & $\begin{array}{r}4.9 \\
\pm 1.3\end{array}$ & 5.4 & 80.0 & 261.9 & 90.8 & 12.8 & 308.7 & 310.2 & 6 \\
\hline 4 & Playa Azul, Mexico & 41 & $\begin{array}{r}0.18 \\
\pm 0.01\end{array}$ & $\begin{array}{r}0.52 \\
\pm 0.02\end{array}$ & $\begin{array}{l}-0.71 \\
\pm 0.02\end{array}$ & $\begin{array}{r}0.28 \\
\pm 0.02\end{array}$ & $\begin{array}{l}-0.44 \\
\pm 0.02\end{array}$ & 0.89 & 27.4 & 75.7 & 280.0 & 63.5 & 97.3 & 116.0 & 5 \\
\hline 5 & El Salvador & 49 & $\begin{array}{l}-0.41 \\
\pm 0.03\end{array}$ & $\begin{array}{l}-1.17 \\
\pm 0.05\end{array}$ & $\begin{array}{r}1.04 \\
\pm 0.03\end{array}$ & $\begin{array}{r}0.48 \\
\pm 0.03\end{array}$ & $\begin{array}{l}-0.47 \\
\pm 0.03\end{array}$ & 1.4 & 60.7 & 286.9 & 302.6 & 33.4 & 242.6 & 90.8 & 7 \\
\hline 6 & New Ireland & 75 & $\begin{array}{r}3.5 \\
\pm 0.2\end{array}$ & $\begin{array}{l}-4.0 \\
\pm 0.5\end{array}$ & $\begin{array}{l}-6.0 \\
\pm 0.4\end{array}$ & $\begin{array}{l}-0.6 \\
\pm 0.1\end{array}$ & $\begin{array}{r}1.7 \\
\pm 0.1\end{array}$ & 7.2 & 40.4 & 109.2 & 162.4 & 52.3 & 74.3 & 317.8 & 11 \\
\hline 7 & Chagos Bank & 31 & $\begin{array}{l}-1.0 \\
\pm 0.1\end{array}$ & $\begin{array}{l}-6.0 \\
\pm 0.2\end{array}$ & $\begin{array}{r}5.3 \\
\pm 0.1\end{array}$ & $\begin{array}{l}-1.6 \\
\pm 0.3\end{array}$ & $\begin{array}{r}5.5 \\
\pm 0.3\end{array}$ & 8.3 & 68.1 & 274.6 & 104.4 & 22.4 & 258.7 & 272.3 & 5 \\
\hline 8 & Valparaiso, Chile & 44 & $\begin{array}{l}-0.14 \\
\pm 0.3\end{array}$ & $\begin{array}{l}-7.5 \\
\pm 0.6\end{array}$ & $\begin{array}{r}-8.6 \\
\pm 0.4\end{array}$ & $\begin{array}{r}9.3 \\
\pm 0.5\end{array}$ & $\begin{array}{l}-0.5 \\
\pm 0.5\end{array}$ & 12.8 & 21.0 & 95.2 & 3.6 & 69.1 & 88.0 & 178.1 & 5 \\
\hline 9 & Michoacan, Mexico & 24 & $\begin{array}{r}2.2 \\
\pm 0.1 \\
\end{array}$ & $\begin{array}{r}4.5 \\
\pm 0.3 \\
\end{array}$ & $\begin{array}{l}-6.3 \\
\pm 0.2 \\
\end{array}$ & $\begin{array}{l}-1.8 \\
\pm 0.4 \\
\end{array}$ & $\begin{array}{l}-7.5 \\
\pm 0.4\end{array}$ & 10.5 & 24.4 & 128.9 & 308.4 & 71.2 & 74.0 & 86.8 & 12 \\
\hline
\end{tabular}

Moment tensor is in units of $10^{27} \mathrm{dyn} \mathrm{cm} ; \mathrm{M}_{\mathrm{o}}$ and $\mathrm{m}_{\mathrm{o}}$ are the scalar moments of the major double couple and minor double couple, respectively; depth is for the centroid; $\delta_{i}$ is the dip, $\lambda_{i}$ the rake, and $\phi_{i}$ the strike in degree.

depth of the earthquake in the range from 0 to $30 \mathrm{~km}$ for the assumed source time $\tau=60$ to $75 \mathrm{~s}$ using long-period Rayleigh waves. Silver and Jordan [1983] estimated the depth of the earthquake to be about $29 \mathrm{~km}$.

We determined the delay time and source process time of the earthquake to be 58 and $118 \mathrm{~s}$, respectively, from long-period Rayleigh waves. The source directivity of the earthquake is represented by a unilateral rupture $256 \mathrm{~km}$ long with a rupture velocity of $2.5 \mathrm{~km} / \mathrm{s}$ to $N 31^{\circ} \mathrm{E}$ and the ratio of rise time to rupture time $\gamma=0.1(\mathrm{ZK})$. We inverted the spectra corrected for the source finiteness at periods of $150,175,200,225,256$, 275 , and $300 \mathrm{~s}$ to determine $D(\omega)$ by solving (4). Then, for each trial depth, we inverted (5) for a moment tensor or a double couple. We determined the depth of the moment tensor or double couple which minimizes the error in the inversion.

In calculating the amplitude spectrum of $\hat{V}$ from the observed spectrum, values of group velocities and $Q$ are required. The inversion of (5) is made with excitation functions computed for a given earth model. Since the ColombiaEcuador earthquake is the largest among the earthquakes studied here, we determined its depth using various models of source finiteness, wave propagation, and excitation. First, we examined the effects of the source-finiteness model on the depth determination using the combination (K70, 5.08M).
Figure 3 shows the RMS error in the moment tensor inversion as a function of the assumed centroid depth for various source-finiteness models for the Colombia-Ecuador earthquake. The minimum of each error curve gives the estimate of the centroid depth for each model. There are significant differences between the estimates of the depth for different sourcefiniteness models. The point source model has the largest depth, $102 \mathrm{~km}$. The estimates of the depth for the models of the time delay and the point source with finite duration are 53 and $32 \mathrm{~km}$, respectively.

For other earthquakes, we also compared the estimates of the depth for these different source-finiteness models. Table 4 lists the results for the centroid depth obtained for different sourcefiniteness models for each earthquake. For all the earthquakes studied here the inversion places the centroid at the largest depth for the point source model, and places the centroid for the time delay model at a depth larger than that for the point source model with finite duration. The differences in depths for models with a source delay time and with a finite duration are significant for most of the earthquakes studied here.

For the Colombia-Ecuador earthquake, the centroid depth was determined at $19 \mathrm{~km}$ for the finite-fault model (Figure 3), which is significantly shallower than that for the point source model of finite duration. For other earthquakes, no systematic

TABLE 3. Centroid Depths Determined in This Study

\begin{tabular}{llccc}
\multicolumn{5}{c}{ Compared With CMT Depths } \\
\hline Event & \multicolumn{1}{c}{ Location } & $\begin{array}{c}\text { Depth, } \\
\text { km }\end{array}$ & Depth Range * & CMT \\
\hline 1 & Colombia-Ecuador & 11 & $9-24$ & 20 \\
2 & Santa Cruz Island & 36 & $18-46$ & 34 \\
3 & Samoa & 15 & $9-26$ & 20 \\
4 & Playa Azul, Mexico & 41 & $28-49$ & 32 \\
5 & El Salvador & 49 & $41-55$ & 52 \\
6 & New Ireland & 75 & $72-79$ & 70 \\
7 & Chagos Bank & 31 & $16-41$ & 10 fixed \\
8 & Valparaiso, Chile & 44 & $15-54$ & 41 \\
9 & Michoacan, Mexico & 24 & $12-34$ & 21 \\
\hline
\end{tabular}

* The depth range is for $90 \%$ confidence. 


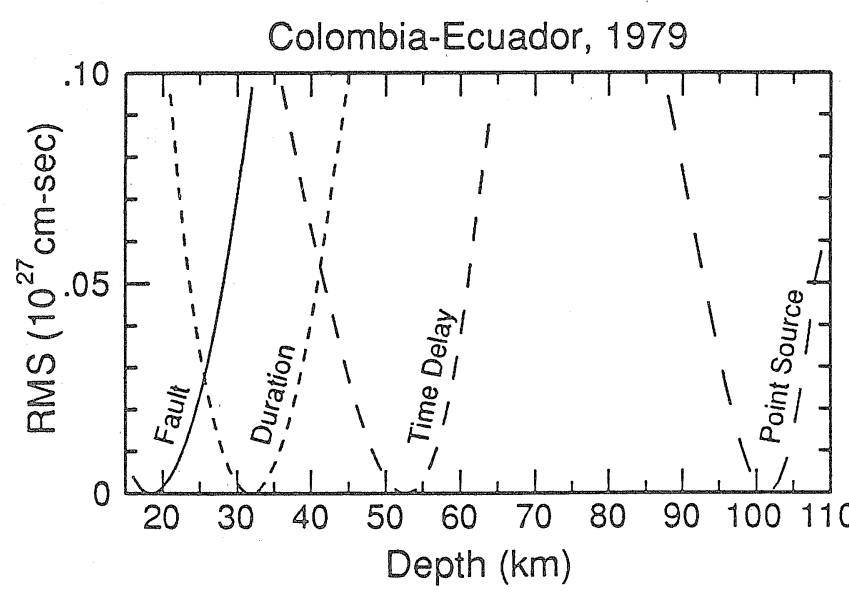

Fig. 3. Colombia-Ecuador earthquake. Residual versus depth curves for the moment tensor inversion are given for four different sourcefiniteness models: step-function point source; constant time delay, $\tau_{\mathrm{d}}=$ $58 \mathrm{~s}$; point source with finite duration, $\mathrm{t}_{\mathrm{s}}=118 \mathrm{~s}, \tau=\mathrm{t}_{\mathrm{f}} / 10$; and finite-fault model, $\mathrm{L}=256 \mathrm{~km}, \mathrm{v}=2.5 \mathrm{~km} / \mathrm{sec}, \phi_{\mathrm{f}}=31^{\circ}, \tau=0.1 \times \mathrm{L} / \mathrm{v}$. The models $\mathrm{K} 70$ and $5.08 \mathrm{M}$ are used for attenuation and excitation, respectively. Each curve is plotted relative to its minimum.

difference between the depths obtained for the two models was found.

Figures $4 \mathrm{a}$ and $4 \mathrm{~b}$ show the $R M S$ error versus centroid-depth curves for the finite-fault model from the moment tensor inversion and fault inversion, respectively. The estimates of the depth obtained from the two methods are the same, $19 \mathrm{~km}$. The estimate is consistent with the CMT depth, $20 \mathrm{~km}$, obtained by Giardini et al. [1985].

Since the earthquake generated a large tsunami and an extensive subsidence on the coast of the Colombia, the rupture of the earthquake may have reached the surface. Using the excitation functions computed by Kanamori and Given [1981] for a distributed source with uniform dislocation extending from the surface to a certain depth, we inverted the data for the moment tensor and double couple to determine the depth extent of the faulting. The estimates of the depth extent are $30 \mathrm{~km}$ from the moment tensor inversion and $33 \mathrm{~km}$ from the fault inversion. Figure $4 c$ shows the $R M S$ error versus depth extent curve from the moment tensor inversion, which has a minimum at $30 \mathrm{~km}$.

Table 5 lists the moment tensor solution for the centroid depth at $19 \mathrm{~km}$, which is essentially a pure double couple. In Figure $4 \mathrm{~d}$, the major double couple of the moment tensor is compared with the solution of model (4) of Kanamori and Given [1981]. Our results agree well with theirs. Table 6 lists the fault solution, which indicates thrust faulting toward the
Colombia-Ecuador, 1979

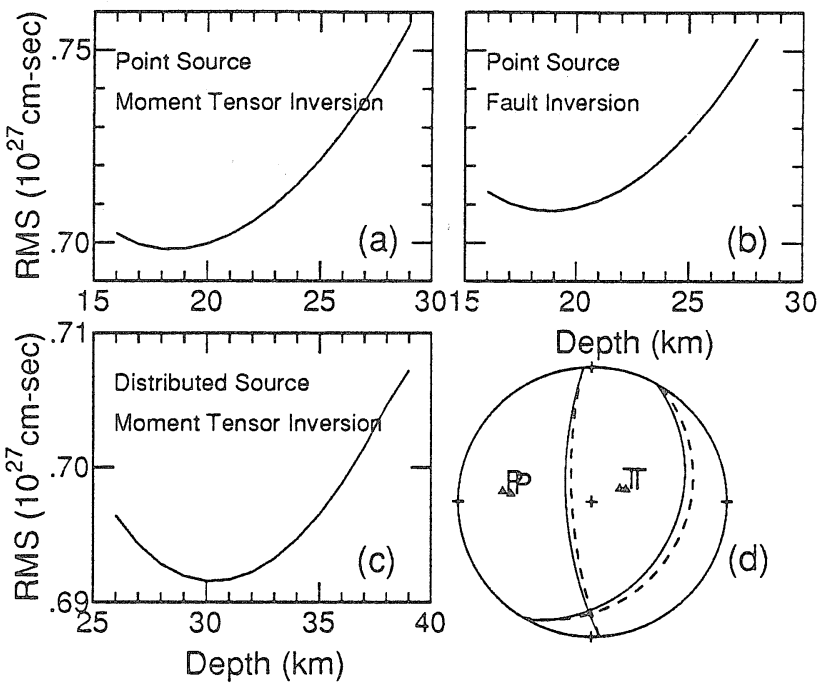

Fig. 4. Colombia-Ecuador earthquake. Residual versus depth curves are given for the finite-fault model. (a) Point source (centroid) by the moment tensor inversion; (b) point source (centroid) by the fault inversion; (c) distributed source by the moment tensor inversion; (d) the mechanism of the major double couple listed in Table 5 (solid line) is compared with the model (4) of Kanamori and Given [1981] (dashed line). The models $\mathrm{K} 70$ and $5.08 \mathrm{M}$ are used.

east with a small right-lateral strike-slip component and a scalar moment $M_{o}=14.1 \times 10^{27} \mathrm{dyn} \mathrm{cm}$. The fault plane extend from the surface to about $33 \mathrm{~km}$ deep with the centroid at a depth of $19 \mathrm{~km}$.

We now examine the effect of various models of wave propagation and excitation on the depth estimate of the earthquake. Figure 5 shows the RMS errors in the moment tensor inversion for the depth range from 10 to $30 \mathrm{~km}$ for several models of group velocity, $Q$, and excitation function with source-finiteness effects corrected for using the finite-fault model.

Figure 5a shows the results for different models of $Q$ using the excitation functions computed for $5.08 \mathrm{M}$. We used three models of Q: K70, PREM, and D-S. The estimate of the depth obtained using K70 is deeper than that using PREM and D-S.

Figure $5 \mathrm{~b}$ shows the results for different models of excitation functions using D-S for $\mathrm{Q}$. We used three models of excitation functions: 5.08M, PREM, and R-A. PREM gives a deeper depth than $5.08 \mathrm{M}$ and R-A.

Figure $5 \mathrm{c}$ shows the results for three combinations of models: (K70, 5.08M), (PREM, PREM), and (D-S, R-A). The depth obtained with the last model is $11 \mathrm{~km}$.

TABLE 4. Centroid Depths (in Kilometers) Determined Using Various Source-Finiteness Models by Moment Tensor Inversion With (D-S, R-A)

\begin{tabular}{clcccc}
\hline Event & \multicolumn{1}{c}{ Location } & $\begin{array}{c}\text { Point } \\
\text { Source }\end{array}$ & $\begin{array}{c}\text { Time } \\
\text { Delay }\end{array}$ & Duration & Fault \\
\hline 1 & Colombia-Ecuador & 99 & 41 & 20 & 11 \\
2 & Santa Cruz Island & 62 & 45 & 28 & 36 \\
3 & Samoa & 37 & 17 & 14 & 15 \\
4 & Playa Azul, Mexico & 54 & 42 & 40 & 41 \\
5 & El Salvador & 55 & 55 & 54 & 49 \\
6 & New Ireland & 75 & 76 & 75 & 75 \\
7 & Chagos Bank & 55 & 38 & 29 & 31 \\
8 & Valparaiso, Chile & 66 & 50 & 43 & 44 \\
9 & Michoacan, Mexico & 73 & 38 & 23 & 24 \\
\hline
\end{tabular}




\section{Colombia-Ecuador, 1979}

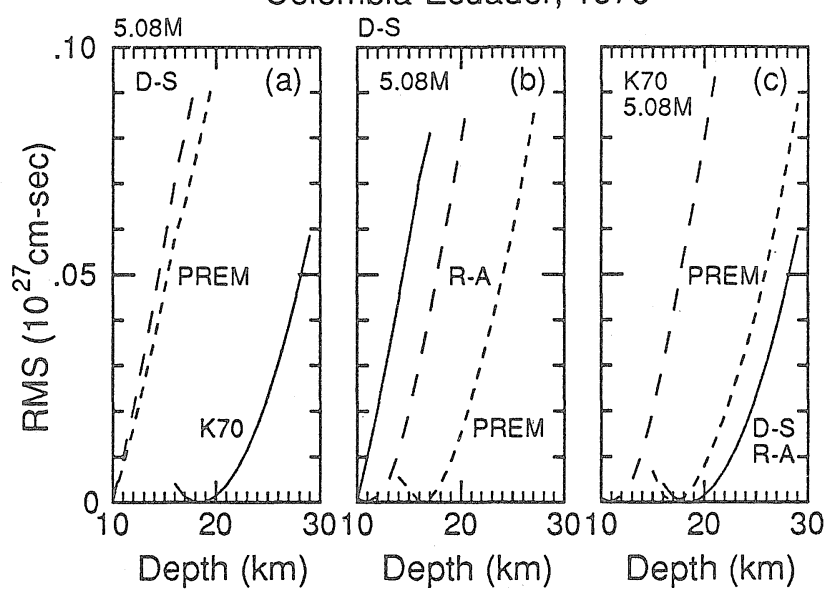

Fig. 5. Colombia-Ecuador earthquake. Residual versus depth curves by the moment tensor inversion are given for the finite-fault model for verious models of $\mathrm{Q}$, group velocity, and excitation. (a) The model $5.08 \mathrm{M}$ is used for the excitation and K70, PREM, D-S for Q and the group velocity. (b) The model D-S is used for $Q$ and the group velocity and 5.08M, PREM, R-A for the excitation. (c) The models D-S and R-A, PREM, and K70 and 5.08M are used for attenuation and excitation. Each curve is plotted relative to its minimum.

As we have illustrated above, the depth estimate depends on the choice of the source-finiteness model, Q model, and excitation functions. For the 1979 Colombia-Ecuador earthquake, if we used the most reasonable source-finiteness model, we obtained a range of 10 to $20 \mathrm{~km}$ for the estimate of the centroid depth. For a very shallow depth (e.g., less than $15 \mathrm{~km}$ ) the inversion becomes unstable with the solution changing rapidly for a small change of the assumed depth [Kanamori and Given, 1981]. The results obtained above indicate that the centroid depth of the Colombia-Ecuador earthquake is shallower than 20 $\mathrm{km}$. In Table 2, the result obtained for (D-S, R-A) with a fixed dip angle of $15^{\circ}$ is listed.

From the dip angle $\left(25^{\circ}\right)$, the depth extent $(33 \mathrm{~km})$, and the rupture length $(256 \mathrm{~km})$, we calculated the width and the area of the fault: $W=70 \mathrm{~km}, A=2 \times 10^{4} \mathrm{~km}^{2}$. Using the rigidity $\mu=5 \times 10^{11} \mathrm{dyn} / \mathrm{cm}^{2}$, we have the average dislocation

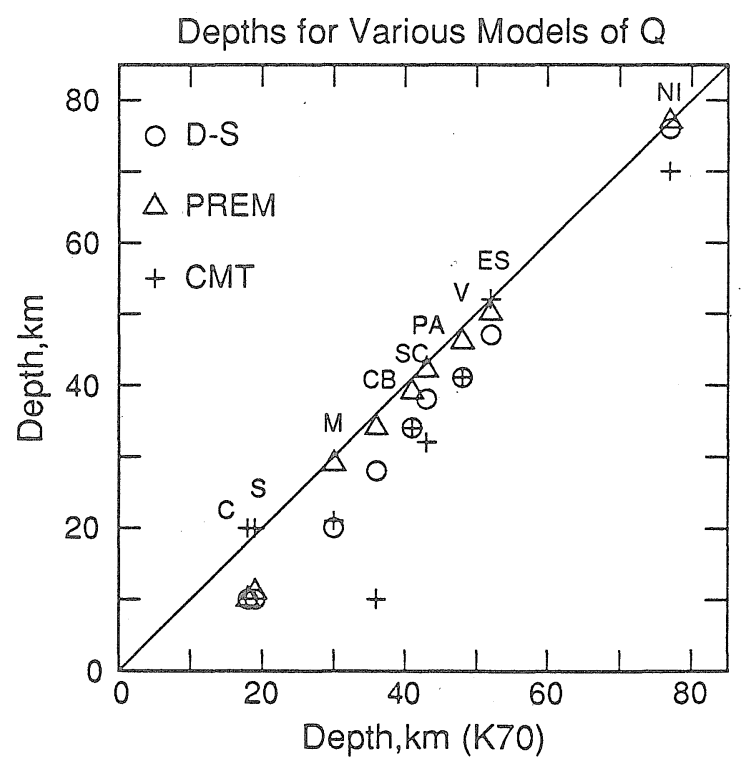

Fig. 6. The depths obtained by the moment tensor inversion with various $\mathrm{Q}$ models using the excitation functions computed for $5.08 \mathrm{M}$. The earthquakes are Colombia-Ecuador (C), Santa Cruz Island (SC), Samoa (S), Playa Azul, Mexico (PA), El Salvador (ES), New Ireland (NI), Chagos Bank (CB), Valparaiso, Chile (V), and Michoacan, Mexico (M). The depths for D-S (circles), PREM (triangles), and Harvard CMT solutions (crosses) are plotted versus the depth for K70.

$\bar{D}=M_{o} / \mu A \sim 1.4 m$, and the stress drop $\Delta \sigma=8 \mu \bar{D} / 3 \pi W \sim 8$ bars for a scalar moment $M_{o}=14 \times 10^{27}$ dyn $\mathrm{cm}$.

The depth estimates of all the earthquakes studied here for various combinations of $\mathbf{Q}$ models and excitation functions are summarized in Figures 6 and 7. The results are listed in Tables 2,5 , and 6 .

\subsection{Santa Cruz IIsland Earthquake}

The July 17, 1980, Santa Cruz Island earthquake occurred in the northem region of the New Hebrides island arc. The arc extends from latitude $11^{\circ} \mathrm{S}$ to $21^{\circ} \mathrm{S}$ and forms a part of the boundary between the Pacific and Australian plates. To the west of the Santa Cruz volcanic chain, the northern New

TABLE 5. Results by Moment Tensor Inversion With (K70, 5.08M)

\begin{tabular}{|c|c|c|c|c|c|c|c|c|c|c|c|c|c|c|c|}
\hline \multirow{2}{*}{ Event } & \multirow{2}{*}{ Location } & \multirow{2}{*}{$\begin{array}{c}\text { Depth, } \\
\mathrm{km}\end{array}$} & \multirow[b]{2}{*}{$M_{x y}$} & \multirow[b]{2}{*}{$M_{y y}-M_{x x}$} & \multirow[b]{2}{*}{$\mathrm{M}_{\mathrm{yy}}+\mathrm{M}_{\mathrm{xx}}$} & \multirow{2}{*}{$\mathrm{M}_{\mathrm{yz}}$} & \multirow[b]{2}{*}{$\mathrm{M}_{\mathrm{xz}}$} & \multicolumn{7}{|c|}{ Major Double Couple } & \multirow{2}{*}{$\begin{array}{c}\mathrm{m}_{\mathrm{o}} / \mathrm{M}_{\mathrm{o}} \\
\% \\
\end{array}$} \\
\hline & & & & & & & & $\mathrm{M}_{0}$ & $\delta_{1}$ & $\lambda_{1}$ & $\phi_{1}$ & $\delta_{2}$ & $\lambda_{2}$ & $\phi_{2}$ & \\
\hline 1 & Colombia-Ecuador & 19 & $\begin{array}{l}-2.5 \\
\pm 0.2\end{array}$ & $\begin{array}{l}-9.6 \\
\pm 0.4\end{array}$ & $\begin{array}{r}-10.3 \\
\pm 0.2\end{array}$ & $\begin{array}{r}10.4 \\
\pm 2.7\end{array}$ & $\begin{array}{l}-2.1 \\
\pm 2.7\end{array}$ & 15.2 & 25.1 & 119.5 & 28.6 & 68.3 & 77.0 & 176.6 & 5 \\
\hline 2 & Santa Cruz Island & 41 & $\begin{array}{r}1.6 \\
\pm 0.2\end{array}$ & $\begin{array}{l}-5.7 \\
\pm 0.3\end{array}$ & $\begin{array}{l}-6.1 \\
\pm 0.2\end{array}$ & $\begin{array}{r}2.8 \\
\pm 0.3\end{array}$ & $\begin{array}{r}0.3 \\
\pm 0.3\end{array}$ & 6.9 & 34.0 & 76.6 & 337.8 & 57.0 & 98.9 & 173.8 & 1 \\
\hline 3 & Samc & 19 & $\begin{array}{l}-0.76 \\
\pm 0.1\end{array}$ & $\begin{array}{l}-2.18 \\
\pm 0.2\end{array}$ & $\begin{array}{c}1.74 \\
\pm 0.1\end{array}$ & $\begin{array}{l}-0.02 \\
\pm 0.6\end{array}$ & $\begin{array}{c}2.33 \\
\pm 0.6\end{array}$ & 3.2 & 70.5 & 258.2 & 93.5 & 22.7 & 300.1 & 205.7 & 10 \\
\hline 4 & Playa Azul, Mexico & 43 & $\begin{array}{r}0.18 \\
\pm 0.01\end{array}$ & $\begin{array}{r}0.50 \\
\pm 0.02\end{array}$ & $\begin{array}{l}-0.76 \\
\pm 0.02\end{array}$ & $\begin{array}{r}0.27 \\
\pm 0.02\end{array}$ & $\begin{array}{l}-0.42 \\
\pm 0.02\end{array}$ & 0.92 & 28.4 & 78.0 & 282.0 & 62.2 & 96.4 & 115.5 & 9 \\
\hline 5 & El Salvac & 52 & $\begin{array}{l}-0.40 \\
\pm 0.03\end{array}$ & $\begin{array}{l}-1.15 \\
\pm 0.05\end{array}$ & $\begin{array}{r}1.14 \\
\pm 0.03\end{array}$ & $\begin{array}{r}0.46 \\
\pm 0.03\end{array}$ & $\begin{array}{l}-0.45 \\
\pm 0.03\end{array}$ & 1.4 & 59.1 & 285.1 & 300.9 & 34.0 & 246.4 & 93.2 & 5 \\
\hline 6 & New Ireland & 77 & $\begin{array}{r}3.6 \\
\pm 0.2\end{array}$ & $\begin{array}{r}-3.9 \\
\pm 0.5\end{array}$ & $\begin{array}{r}-5.9 \\
\pm 0.4\end{array}$ & $\begin{array}{l}-0.6 \\
\pm 0.1\end{array}$ & $\begin{array}{r}1.8 \\
\pm 0.1\end{array}$ & 7.2 & 40.3 & 110.1 & 162.2 & 52.6 & 73.7 & 316.6 & 12 \\
\hline 7 & Chagos ıank & 36 & $\begin{array}{l}-0.9 \\
\pm 0.1\end{array}$ & $\begin{array}{l}-6.0 \\
\pm 0.2\end{array}$ & $\begin{array}{r}6.0 \\
\pm 0.1\end{array}$ & $\begin{array}{l}-1.3 \\
\pm 0.2\end{array}$ & $\begin{array}{r}4.5 \\
\pm 0.2\end{array}$ & 7.7 & 63.9 & 274.1 & 103.3 & 26.4 & 261.7 & 270.0 & 2 \\
\hline 8 & hile & 48 & $\begin{array}{l}-0.21 \\
\pm 0.3\end{array}$ & $\begin{array}{l}-7.3 \\
\pm 0.6\end{array}$ & $\begin{array}{l}-9.4 \\
\pm 0.4\end{array}$ & $\begin{array}{r}8.2 \\
\pm 0.5\end{array}$ & $\begin{array}{l}-0.5 \\
\pm 0.5\end{array}$ & 12.6 & 23.7 & 95.4 & 4.2 & 66.4 & 87.6 & 178.3 & 8 \\
\hline 9 & Michoacan, Mexico & 30 & $\begin{array}{r}2.2 \\
\pm 0.1 \\
\end{array}$ & $\begin{array}{r}4.5 \\
\pm 0.3 \\
\end{array}$ & $\begin{array}{r}-7.1 \\
\pm 0.2 \\
\end{array}$ & $\begin{array}{l}-1.2 \\
\pm 0.4 \\
\end{array}$ & $\begin{array}{r}-5.1 \\
\pm 0.4 \\
\end{array}$ & 9.2 & 30.8 & 119.1 & 306.2 & 63.4 & 73.9 & 93.2 & 13 \\
\hline
\end{tabular}


TABLE 6. Results by Fault Inversion With (K70, 5.08M)

\begin{tabular}{clccrrr}
\hline Event & \multicolumn{1}{c}{ Location } & Depth, $\mathrm{km}$ & \multicolumn{1}{c}{$\mathrm{M}_{\mathrm{o}}$} & \multicolumn{1}{c}{$\delta$} & \multicolumn{1}{c}{$\phi$} \\
\hline 1 & Colombia-Ecuador & 19 & $14.1 \pm 1.6$ & $25.4 \pm 3.9$ & $107.7 \pm 6.3$ & $23.3 \pm 3.7$ \\
2 & Santa Cruz Island & 41 & $6.8 \pm 0.2$ & $34.1 \pm 1.4$ & $76.2 \pm 4.2$ & $337.5 \pm 3.2$ \\
3 & Samoa & 17 & $3.4 \pm 0.7$ & $74.2 \pm 3.8$ & $252.8 \pm 4.3$ & $83.3 \pm 3.0$ \\
4 & Playa Azul, Mexico & 42 & $0.87 \pm 0.02$ & $27.6 \pm 0.9$ & $79.6 \pm 3.7$ & $282.8 \pm 2.8$ \\
5 & El Salvador & 51 & $1.4 \pm 0.03$ & $59.7 \pm 0.8$ & $285.9 \pm 1.6$ & $301.8 \pm 1.5$ \\
6 & New Ireland & 78 & $7.1 \pm 0.3$ & $40.1 \pm 0.7$ & $106.1 \pm 2.1$ & $159.6 \pm 2.9$ \\
7 & Chagos Bank & 36 & $7.6 \pm 0.2$ & $63.9 \pm 0.8$ & $274.5 \pm 3.3$ & $103.7 \pm 2.3$ \\
8 & Valparaiso, Chile & 44 & $12.1 \pm 0.5$ & $21.1 \pm 1.1$ & $95.2 \pm 5.9$ & $3.9 \pm 4.8$ \\
9 & Michoacan, Mexico & 30 & $8.3 \pm 0.4$ & $29.3 \pm 2.0$ & $107.6 \pm 5.6$ & $301.3 \pm 3.7$ \\
\hline
\end{tabular}

Hebrides trench is well developed with a strike of $N 20^{\circ} \mathrm{W}$. The earthquake is located to the east of, and very close to, the trench axis, where the oceanic trench starts to bend westward. The CMT depth of the earthquake is $34 \mathrm{~km}$. In this region the Australian plate moves $N 75^{\circ} E$ with respect to the Pacific plate [Le Pichon, 1968; Chase, 1971; Molnar and Sykes, 1971; Johnson and Molnar, 1972]. The focal mechanisms of the large New Hebrides events that occurred through 1970 to the north of $16^{\circ}$ latitude show shallow thrust faulting with a consistent east-northeast slip vector [Johnson and Molnar, 1972].

The July $17,1980\left(M_{s}=7.9\right)$, earthquake occurred about 50 $\mathrm{km}$ away to the west of the epicenter of the July 8, 1980 $\left(M_{s}=7.5\right)$, earthquake. The aftershocks of the two earthquakes are not clearly distinguishable. From the Preliminary Determination of Epicenters (PDE) listings of the NEIC, the aftershocks between July 8 and July 17 are distributed to the south of the epicenter of the July 8 earthquake; however, after the July 17 earthquake, most of the aftershocks occurred to the north of the epicenter of the July 17 earthquake. The aftershocks after the July 17 earthquake are distributed in an area about $120 \mathrm{~km}$ long, and the aftershock area did not expand significantly. The close location of the two large earthquakes and the abrupt change of the location of the seismic activity before and after the July 17 event suggest that both the July 8

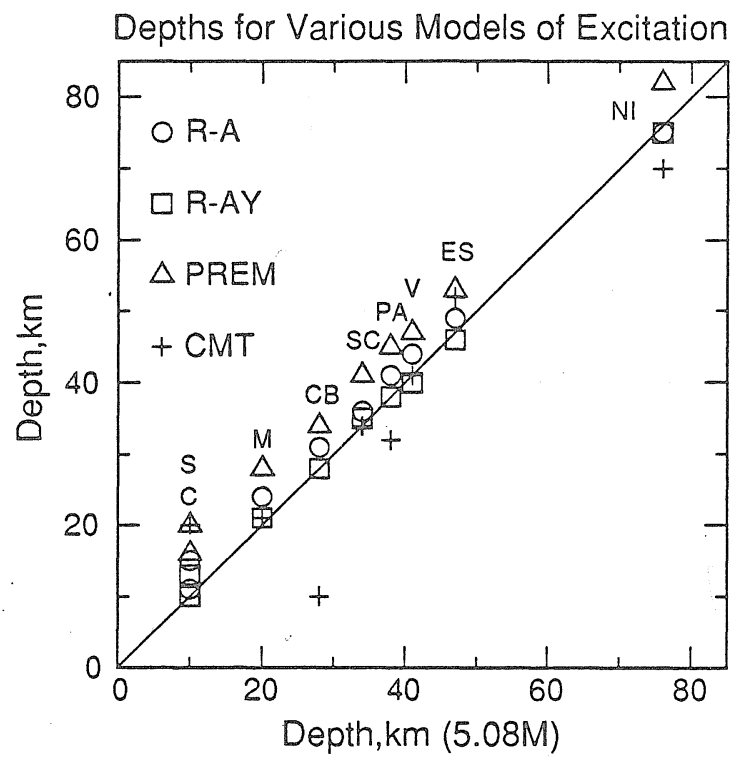

Fig. 7. The depths obtained by the moment tensor inversion with various models of excitation functions using the D-S Q model. The excitation functions are for the models of 5.08M (solid line), PREM (triangles), R-A (circles), and R-AY (squares). Harvard CMT depths are shown by crosses. The depths obtained are plotted versus the depth for model $5.08 \mathrm{M}$ for each earthquake. and July 17 events initiated at almost the same site, but the first event ruptured to the south and the second ruptured to the north. We considered the aftershock area of the July 17 event to be about $120 \mathrm{~km}$ long to the north, which is consistent with the analysis of the earthquake sequence ( $F$. Tajima et al., manuscript in preparation, 1988).

We determined the rupture length and azimuth of the July 17 earthquake. The inversions of the spectra indicate that the rupture of the earthquake is unilateral to the north of the epicenter. Figures $8 \mathrm{a}$ and $8 \mathrm{~b}$ show the rupture length and the rupture azimuth estimated for various ratios of the rise time, $\tau$, to rupture time, $t_{f}\left(\gamma=\tau / t_{f}\right)$, and several rupture velocities $V$, respectively. Using $V=2 \mathrm{~km} / \mathrm{s}$ and $\gamma=0.5$, the estimates of the rupture length and the rupture azimuth are $114 \mathrm{~km}$ and $N 22^{\circ} \mathrm{W}$, respectively. These estimates are consistent with the aftershock area and the strike of the trench.

We used this rupture model in the determination of the depth of the earthquake. Although these estimates are subject to errors due to the uncertainties in $V$ and $\gamma_{2}$ we found that using other estimates obtained for different $V$ and $\gamma$ did not significantly change the estimate of the depth. Figure 9a shows the RMS error versus centroid-depth curve for the moment tensor inversion using $(\mathbb{K} 70,5.08 \mathrm{M})$. The moment tensor solution is listed in Table 5, which is almost a pure double couple.

There is no evidence that the earthquake broke the surface. Since the minimum error in the inversion for a centroid source does not significantly differ from that for an extended source, whether the earthquake broke the surface or not cannot be determined from the analysis of long-period surface waves.

Kanamori and Given [1982] used IDA data and found the dip angle of the earthquake to be about $33^{\circ}$ for the source

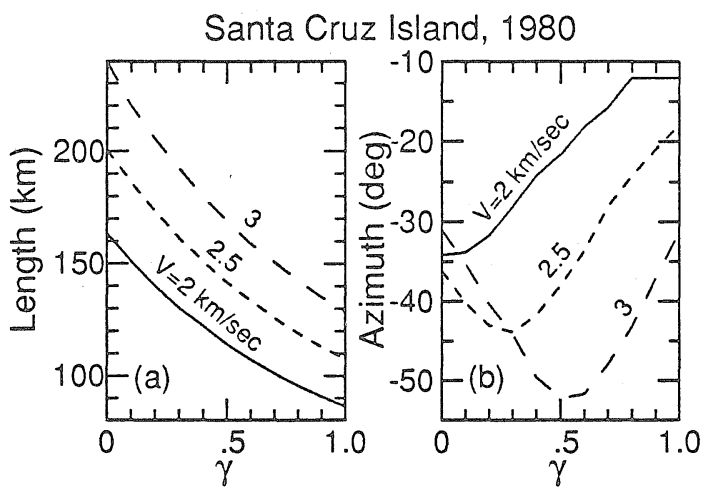

Fig. 8. Santa Cruz Island earthquake. The rupture parameters as functions of the ratio $\gamma$ for the rupture velocities of 2 (solid line), 2.5 (dotted line), and 3 (dashed line) $\mathrm{km} / \mathrm{sec}$. The inversion is at the period $256 \mathrm{~s}$. (a) The rupture length. The rupture is assumed to be unilateral toward the north. (b) The rupture azimuth. The rupture is assumed to be unilateral with a length of $120 \mathrm{~km}$. 
Santa Cruz Island, 1980

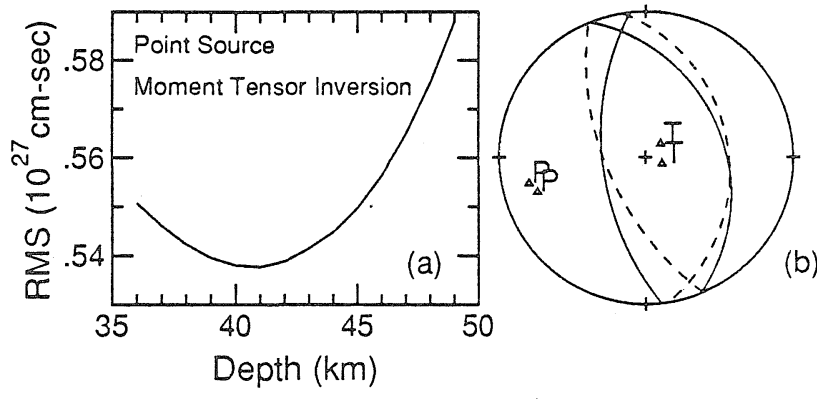

Fig. 9. Santa Cruz earthquake. (a) Residual versus depth curves by the moment tensor inversion are given for the finite-fault model obtained. (b) The source mechanism of the major double couple listed in Table 5 (solid line) is compared with the best double couple of the Harvard CMT solution (dashed line).

depth of $33 \mathrm{~km}$. Nakanishi and Kanamori [1984] examined $P$ wave first-motion data of the earthquake, which allow the dip of one of the nodal planes to vary from $38^{\circ}$ to $55^{\circ}$. They constrained the dip of one nodal plane $\left(\delta=52^{\circ}\right)$ in the inversion of IDA and GDSN data and found the dip angle of another plane to be $38^{\circ}$ for the source depth at $33 \mathrm{~km}$.

An earthquake source is usually represented by a shear dislocation or a double couple. The seismic moment tensor, which represents a more general source than a shear dislocation, can be decomposed into a major double couple and a minor double couple [Kanamori and Given, 1981] or a best double couple and a linear vector dipole [Dziewonski and Woodhouse, 1983]. If the minor double couple or linear vector dipole is very small compared with the major or best double couple, the major double couple is essentially the same as the best double couple. For all the earthquakes studied here, minor double couples are in general very small. In Figure $9 \mathrm{~b}$ the major double couple of the moment tensor determined with $(\mathrm{K} 70,5.08 \mathrm{M})$ is compared with the best double couple of the CMT solution for the Santa Cruz Island earthquake. Our solution is consistent with the CMT solution. The best double couple of the CMT solution has a dip angle of $31^{\circ}$ for the nodal plane dipping to the east. Our moment tensor solution determined with the various combinations of $Q$ and excitation functions has a centroid depth ranging from 36 to $41 \mathrm{~km}$ and a dip angle of the nodal plane ranging from $30^{\circ}$ to $34^{\circ}$. These results are consistent with the results of other studies.

We also estimated the depth using a point source model with 88-s duration determined by $\mathrm{ZK}$; we obtained a centroid depth of $33 \mathrm{~km}$ by the moment tensor inversion and by the fault inversion with $(\mathrm{K} 70,5.08 \mathrm{M})$.

\subsection{Samoa Earthquake}

The September 19, 1981, Samoa Islands earthquake occurred in the northernmost region of the Tonga Island arc between the arc and the trench. In this region the trench abruptly bends westward from $N 20^{\circ} \mathrm{E}$ to $N 70^{\circ} \mathrm{W}$, and shallow earthquakes often cluster. Isacks et al. [1969] found that the shallow earthquakes have steeply dipping E-W-striking fault planes and reflect primarily downward motion of the part of the Pacific plate subducting under the Tonga Islands with respect to the Pacific plate to the north of the Tonga trench (Samoa Islands). The shallow earthquakes are considered to result directly from the relative motion of the two parts of the Pacific plate.
The aftershocks of the earthquake reported from PDE listings of the NEIC are distributed in a zone about $110 \mathrm{~km}$ long extending to SSE. The epicenter of the main shock is close to the northern end of the aftershock area.

In determining the source process time of the earthquake, the errors in the inversion at the periods of 256,275 , and $300 \mathrm{~s}$ are larger than those at the periods of $150,175,200$, and $225 \mathrm{~s}$ $(Z K)$. We assumed that the rupture was in $S 25^{\circ} \mathrm{E}$ direction ( $L_{1}$ direction) parallel to the aftershock area to estimate the rupture length of the earthquake. Results indicate that the rupture is unilateral in this direction. We estimated the rupture length using the inversion at periods of $150,175,200,225,256,275$, and $300 \mathrm{~s}$ separately. The minimum errors obtained at the periods of 256,275 , and $300 \mathrm{~s}$ are larger than those obtained at other periods. This indicates that the source finiteness of the earthquake cannot be determined well from the data at these longer periods. We compared the observability of the source finiteness of the earthquake at all periods.

Figure 10 shows the curves of the average observed amplitude spectrum $\bar{V}(\omega)$, the magnitude of the source-finiteness effect $\bar{S}(\omega)$, and the observability of the source finiteness $\eta(\omega)$ versus period. In the figure the maxima of $\bar{V}(\omega)$ and $\eta(\omega)$ are normalized to 1 in the period range. The source-finiteness effect is calculated using a unilateral rupture $110 \mathrm{~km}$ long along the $L_{1}$ direction with a rupture velocity of $2.5 \mathrm{~km} / \mathrm{s}$. The $\bar{V}(\omega)$ at long periods is about the same as, or slightly larger than, that at short periods. This is different from $\bar{V}(\omega)$ for the Akita-Oki, Colombia-Ecuador, Valparaiso, Michoacan, and Sumbawa earthquakes, which decreases as the period exceeds $256 \mathrm{~s}(\mathrm{ZK})$. For the Samoa earthquake, the minimum error for the inversion at short periods is smaller than that at long periods, and the magnitude of the source-finiteness effects at short periods is larger than at long periods. The overall observability of the source finiteness at short periods becomes larger than at long periods. In Figure 10, $\eta(\omega)$ is largest at $175 \mathrm{~s}$. Therefore we used the data set of the 175-s period to estimate the source finiteness of the earthquake.

Figures $11 \mathrm{a}$ and $11 \mathrm{~b}$ show the rupture length and rupture azimuth versus $\gamma$ curves for rupture velocities $V=2,2.5$, and 3 $\mathrm{km} / \mathrm{s}$. For $\mathrm{V}=2.5 \mathrm{~km} / \mathrm{s}$ and $\gamma=0.1$ the estimates of the rupture length and the rupture azimuth are $107 \mathrm{~km}$ and $113^{\circ}$, respectively, which are consistent with the aftershock area.

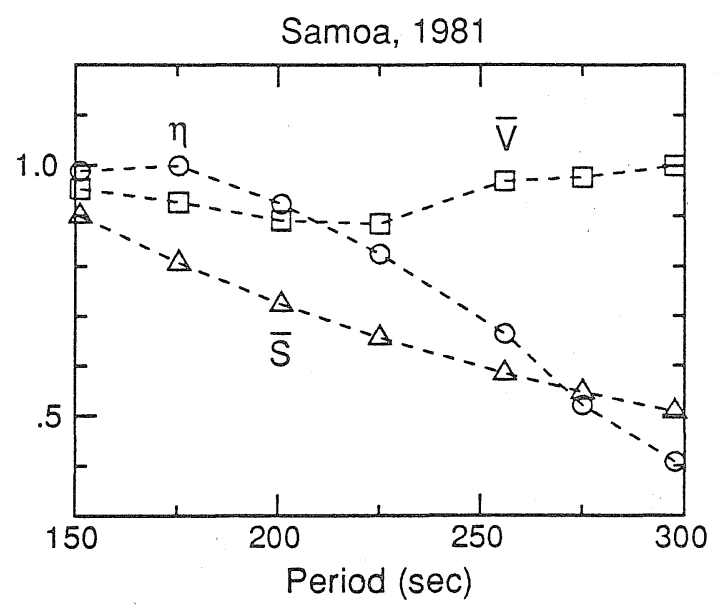

Fig. 10. Samoa earthquake. $\bar{V}(\omega)$ (squares), $\bar{S}(\omega)$ (triangles), and $\eta(\omega)$ (circles) at various periods. 
In determining the depth, we used a unilateral rupture 107 $\mathrm{km}$ long with a rupture velocity of $2.5 \mathrm{~km} / \mathrm{s}$ in the azimuth of $113^{\circ}$ and $\gamma=0.1$. Figure $12 \mathrm{a}$ shows the $R M S$ error versus centroid-depth curve obtained by the moment tensor inversion (with $(K 70,5.08 \mathrm{M})$ ), which indicates a $19-\mathrm{km}$ depth of the centroid. The moment tensor solution for the depth of $19 \mathrm{~km}$ has a scalar moment of $3.2 \times 10^{27} \mathrm{dyn} \mathrm{cm}$ and normal-fault mechanism for the major double couple. The centroid depth estimated by the fault inversion is $17 \mathrm{~km}$ (Figure $12 \mathrm{~b}$ ). Figure $12 \mathrm{c}$ shows the $R M S$ error versus depth extent curve obtained by the moment tensor inversion, which indicates that the depth extent is $30 \mathrm{~km}$.

Figure $12 \mathrm{~d}$ compares the mechanism of the major double couple of the moment tensor solution for the centroid depth of $19 \mathrm{~km}$ with the $\mathrm{P}$ wave first-motion mechanism reported by the NEIC. If the nodal plane dipping toward the south is the fault plane, the fault motion reflects the southern part of the Pacific plate sliding down with respect to the northern part on a plane steeply dipping to the south. The rupture of the earthquake, unilateral toward the east, suggests that the Pacific plate to the south of the epicenter is tearing off from the surficial part of the Pacific plate to the north, because of the collision of the Pacific plate and the Australian plate.

We also estimated the depth using a point source model with 45 -s duration determined by $\mathrm{ZK}$; we obtained a centroid depth of $22 \mathrm{~km}$ by the moment tensor inversion and of $20 \mathrm{~km}$ by the fault inversion with $(K 70,5.08 \mathrm{M})$.

\subsection{Playa Azul, Mexico, Earthquake}

This earthquake $\left(M_{s}=7.3\right)$ occurred in the center of the Michoacan gap about $40 \mathrm{~km}$ south of the epicenter of the 1985 $\left(M_{s}=8.1\right)$ earthquake [Havskov et al., 1983; UNAM Seismology Group, 1986]. The CMT depth of this earthquake is 32 $\mathrm{km}$. Astiz et al. [1987] obtained a depth of $27 \mathrm{~km}$ from modeling of long-period $\mathrm{P}$ waves recorded by the World-Wide Standardized Seismograph Network (WWSSN).

Aftershocks were recorded by a portable array operated in the epicentral area for 6 days starting 19 hours after the main shock. They are clustered in two groups, one on the northeast and the other on the northwest of the main shock epicenter
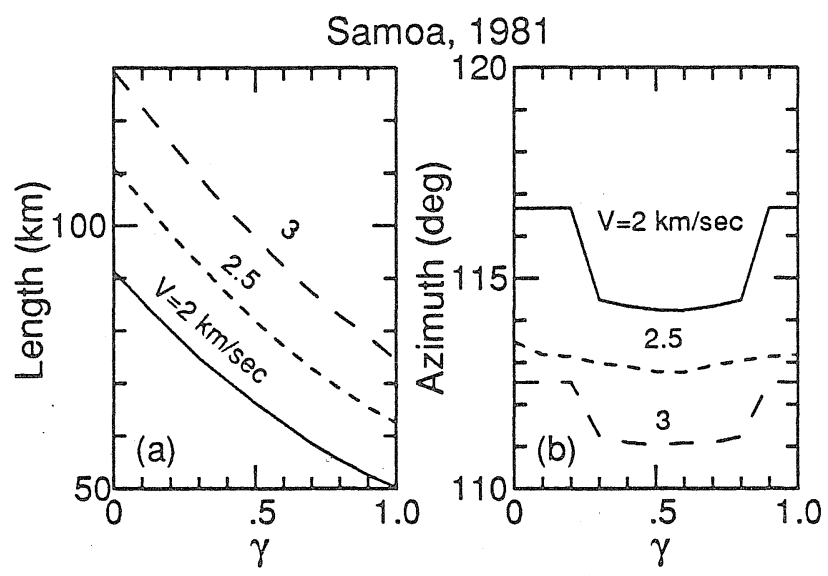

Fig. 11. Samoa earthquake. The rupture parameters as functions of the ratio $\gamma$ for the rupture velocities of 2 (solid line), 2.5 (dotted line), and 3 (dashed line) $\mathrm{km} / \mathrm{sec}$. The inversion is at the period $175 \mathrm{~s}$. (a) The rupture length. The rupture is assumed to be unilateral toward $S 25^{\circ} \mathrm{E}$. (b) The rupture azimuth. The rupture is assumed to be unilateral with a length of $110 \mathrm{~km}$.

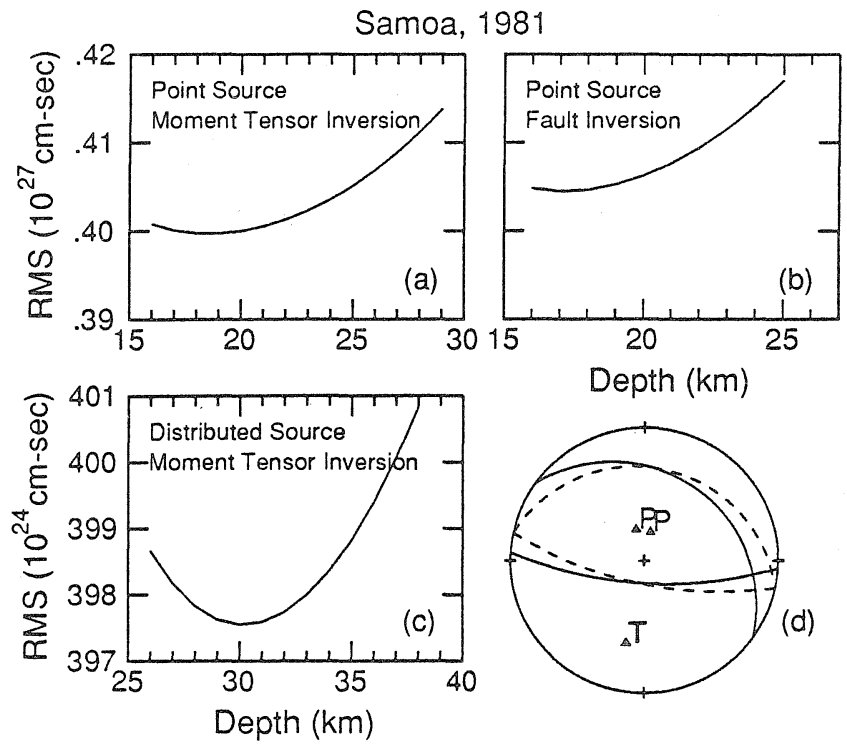

Fig. 12. Samoa earthquake. Residual versus depth curves by the moment tensor inversion are given for the finite-fault model obtained. (a) Point source (centroid) by the moment tensor inversion, (b) point source (centroid) by the fault inversion, (c) distributed source by the moment tensor inversion, and (d) the source mechanism of the major double couple listed in Table 5 (solid line) compared with the best double couple of the Harvard CMT solution (dashed line).

[Havskov et al., 1983]. Some aftershocks are as deep as 26 $\mathrm{km}$. The aftershocks recorded by the array during the 6-day period with a coda duration more than $30 \mathrm{~s}$ are distributed in an area about $40 \mathrm{~km}$ long in the E-W direction parallel to the trench. Since the main shock location (determined from readings of 13 stations within distances less than $450 \mathrm{~km}$ from the epicenter) is less reliable than that of the aftershocks, the relationship between the main shock location and the aftershock area is not clear.

ZK do not examine this event. We used 52 Rayleigh wave phases $R_{1}$ and $R_{2}$ or $R_{2}$ and $R_{3}$ recorded at IDA and GDSN stations ( $R_{1}$ and $R_{2}$ : SPA, SUR, GRFO, GUMO, NWAO, SNZO, TATO, CTAO, KONO, SLR; $R_{2}$ and $R_{3}$ : CMO, KIP, BDF, ERM, ESK, GUA, PFO, RAR, SSB, TWO, ANMO, BOCO, MAJO, JAS, SCP; $R_{2}$ only: LON; $R_{3}$ only: NNA). We computed the spectra of these wave trains and determined the source process time of the earthquake using the linear inversion method of $\mathrm{ZK}$. Figure 13a shows the RMS error of the inversion for various source process times in the range 0 to $140 \mathrm{~s}$ for periods from 150 to $300 \mathrm{~s}$. The spectral data used here are corrected for the propagation phase delay with the model M84C. We obtained a source process time of $42 \mathrm{~s}$, which is the average of the estimates at periods of 256 and $275 \mathrm{~s}$. The source process time is at least twice as long as the rupture time inferred from the aftershock area.

We also used a homogeneous model (HOM) of phase velocities [Gilbert and Dziewonski, 1975] to correct for the phase delay and obtained the source process time. Figure $13 \mathrm{~b}$ shows the source process times obtained for models M84C and HOM from inversions at periods from 200 to $300 \mathrm{~s}$. The model HOM gives estimates $10 \mathrm{~s}$ or more longer than the model M84C. Note that for the 1985 Michoacan, Mexico, earthquake similar results were obtained by $\mathrm{ZK}$ (Figure 13c).

We used $\gamma=1$ and $V=2 \mathrm{~km} / \mathrm{s}$ to estimate the rupture length and the rupture azimuth of the earthquake. If we assumed that 
Playa Azul, Mexico 1981

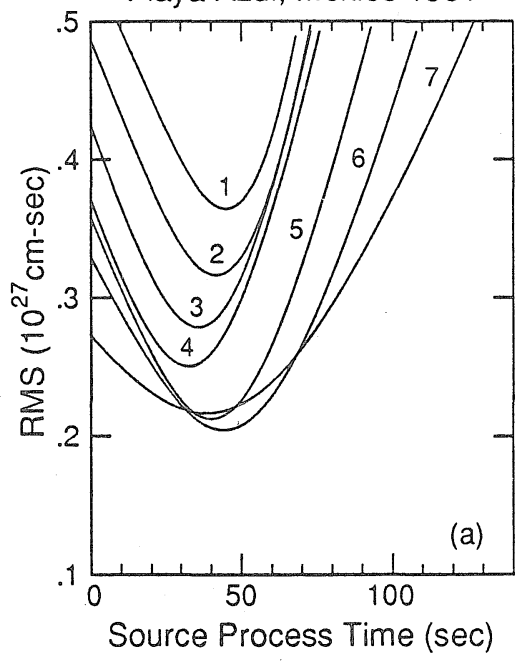

Playa Azul, Mexico 1981

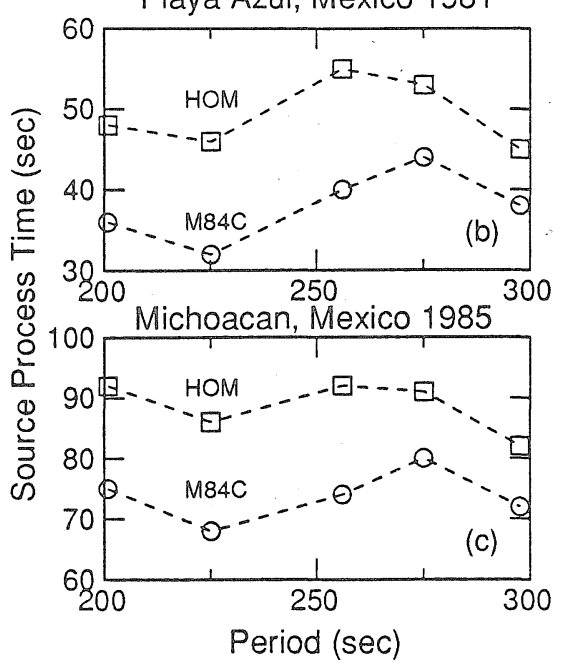

Fig. 13. (a) Playa Azul, Mexico, earthquake. The RMS error plotted versus trial source process time for the inversion at the periods of (1) 150, (2) 175 , (3) 200, (4) 225 , (5) 256 , (6) 275 , and (7) $300 \mathrm{~s}$, respectively. The time corresponding to the minimum error on each curve is taken as the source process time measured at that period. (b) Comparison of the estimated source process times of the Playa Azul, Mexico, earthquake measured at periods of 200,225, 256, 275, and $300 \mathrm{~s}$ by the inversion method for two phase-velocity models; phase velocity is calculated (1) from the average observed normal mode periods compiled by Gilbert and Dziewonski [1975] (HOM) (squares), (2) from a laterally heterogeneous earth model obtained by Woodhouse and Dziewonski [1984] (M84C) (circles). (c) Comparison of the estimated source process times of the Michoacan, Mexico, earthquake for the two phase-velocity models.

the rupture was bilateral, the inversion gives a total rupture length of $80 \mathrm{~km}$ in the direction $N 86^{\circ} \mathrm{E}$, which is consistent with the direction of the aftershock area. For a unilateral rupture the inversion gives a rupture length $40 \mathrm{~km}$ toward $N 57^{\circ} \mathrm{E}$. We used the bilateral rupture to approximate the source finiteness of the earthquake.

Since this earthquake is relatively small, the choice of this particular finiteness model is not critical. Any source-finiteness model with a time constant of $40 \mathrm{~s}$ yielded essentially the same result.

Using a finite-fault model and $(\mathrm{K} 70,5.08 \mathrm{M})$, we obtained a centroid depth of $43 \mathrm{~km}$ from the moment tensor inversion (Figure 14a). The major double couple of the moment tensor solution is compared with the best double couple of the CMT solution in Figure 14b. The centroid depth and mechanism obtained from the moment tensor and the fault inversion are listed in Tables 5 and 6 , respectively.

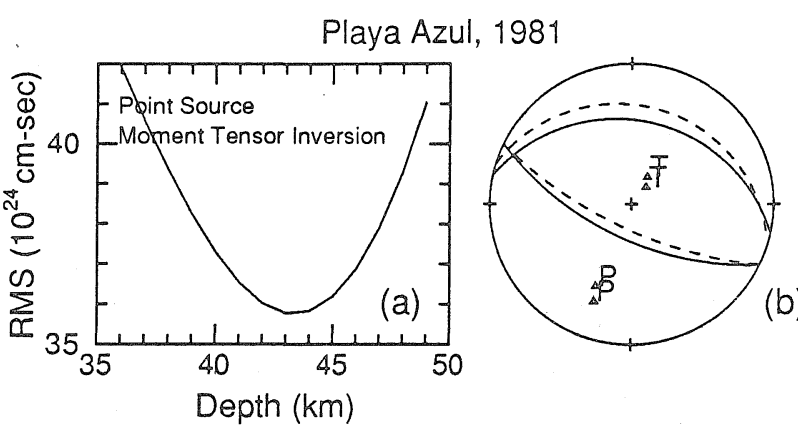

Fig. 14. Playa Azul, Mexico, earthquake. (a) Residual versus depth curves by the moment tensor inversion are given for the finite-fault model obtained. (b) The source mechanism of the major double couple listed in Table 5 (solid line) is compared with the best double couple of the Harvard CMT solution (dashed line).

\subsection{El Salvador Earthquake}

This earthquake occurred at the coast of $\mathbb{E}$ l Salvador between the Middle America trench and the line of historically active volcanoes, where the Cocos plate is moving northerly relative to the Caribbean plate. The earthquake is relatively small $\left(M_{s}=7\right)$ compared with other earthquakes studied here. The depth of the earthquake hypocenter determined by the NEIC is $82 \mathrm{~km}$. The CMT depth is $52 \mathrm{~km}$.

Aftershocks reported from PDE listings of the NEIC are very sparse. A few events located within a distance of about $70 \mathrm{~km}$ to the SSW of the epicenter of the main shock. The inversions of the Rayleigh wave spectra do not constrain well the rupture mode of the earthquake; the minimum of the error curve, which suggests a unilateral rupture, is not well defined. Figures $15 \mathrm{a}$ and $15 \mathrm{~b}$ show the rupture length and the rupture azimuth estimated for a unilateral rupture for various $\gamma$ and $V$, respectively. For $\gamma=0.1$ and $V=2 \mathrm{~km} / \mathrm{s}$ the estimates of the rupture length and the rupture azimuth are $59 \mathrm{~km}$ and $S 17^{\circ} \mathrm{W}$, respectively. These estimates are consistent with the aftershock distribution.

In determining the depth, we used the source-finiteness model of a unilateral rupture $59 \mathrm{~km}$ long toward the $S 17^{\circ} \mathrm{W}$ of the epicenter with a rupture velocity of $2 \mathrm{~km} / \mathrm{s}$ and $\gamma=0.1$. The depths of the centroid obtained by the moment tensor inversion and fault inversion with $(\mathrm{K} 70,5.08 \mathrm{M})$ are 52 and 51 $\mathrm{km}$, respectively. Figure $16 \mathrm{a}$ shows the RMS error versus trial centroid-depth curve for the moment tensor inversion. The moment tensor solution for the depth of $52 \mathrm{~km}$, which is almost a pure double couple, is listed in Table 5. The double couple solution obtained from the fault inversion is listed in Table 6. The solution indicates that the earthquake is primarily a normal fault event with one nodal plane steeply dipping to the NE and parallel to the trench. Figure $16 \mathrm{~b}$ shows the comparison of the major double couple of the moment tensor and the best double 

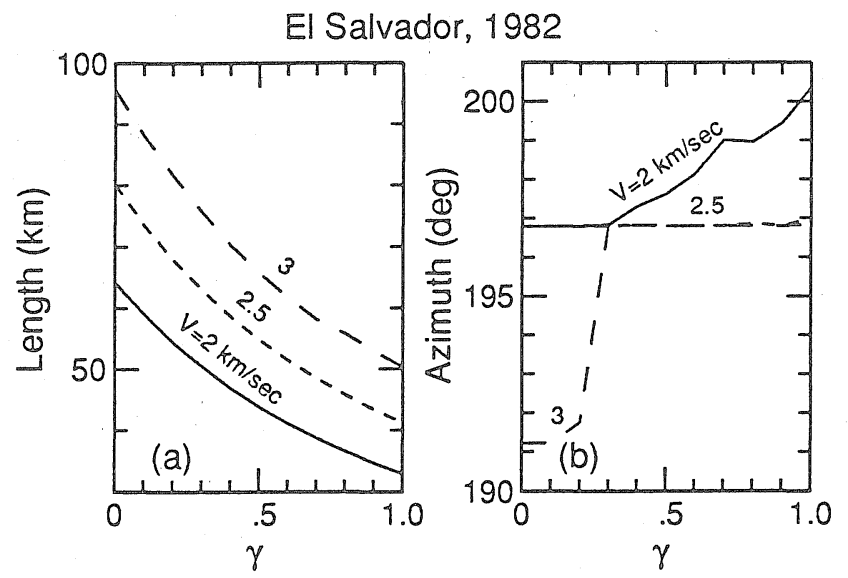

Fig. 15. El Salvador earthquake. The rupture parameters as functions of the ratio $\gamma$ for the rupture velocities of 2 (solid line), 2.5 (dotted line), and 3 (dashed line) $\mathrm{km} / \mathrm{sec}$. The inversion is at the period $256 \mathrm{~s}$. (a) The rupture length. The rupture is assumed to be unilateral toward $\mathrm{S} 25^{\circ} \mathrm{W}$. (b) The rupture azimuth. The rupture is assumed to be unilateral with a length of $70 \mathrm{~km}$.

couple of the CMT solution. Our solution agrees well with the CMT solution.

Using the model of a point source with 35-s duration determined by $Z K$, we obtained a centroid depth of $56 \mathrm{~km}$ by the moment tensor inversion and by the fault inversion with (K70, $5.08 \mathrm{M})$.

\subsection{New Ireland Earthquake}

This earthquake occurred at the northwestern portion of the Solomon arc near the junction of the Solomon and New Britain trenches. Previous studies indicate that the Solomon Sea plate subducts toward the northeast under the Solomon trench and toward the northwest under the New Britain trench [Johnson and Molnar, 1972; Lay and Kanamori, 1980]. The depth of the earthquake hypocenter determined by the NEIC is $89 \mathrm{~km}$. The CMT solution has a depth of $70 \mathrm{~km}$.

Aftershocks of the earthquake from PDE listings of the NEIC are distributed in an area about $120 \mathrm{~km}$ long around the main shock. The inversions of the Rayleigh wave spectra do not constrain well the rupture mode of the earthquake. Figures 17a and $17 \mathrm{~b}$ show the rupture length (one side from the epicenter) and the rupture azimuth estimated for a bilateral rupture for various $\gamma$ and $V$, respectively. For $\gamma=0.1$ and $V=2 \mathrm{~km} / \mathrm{s}$, the

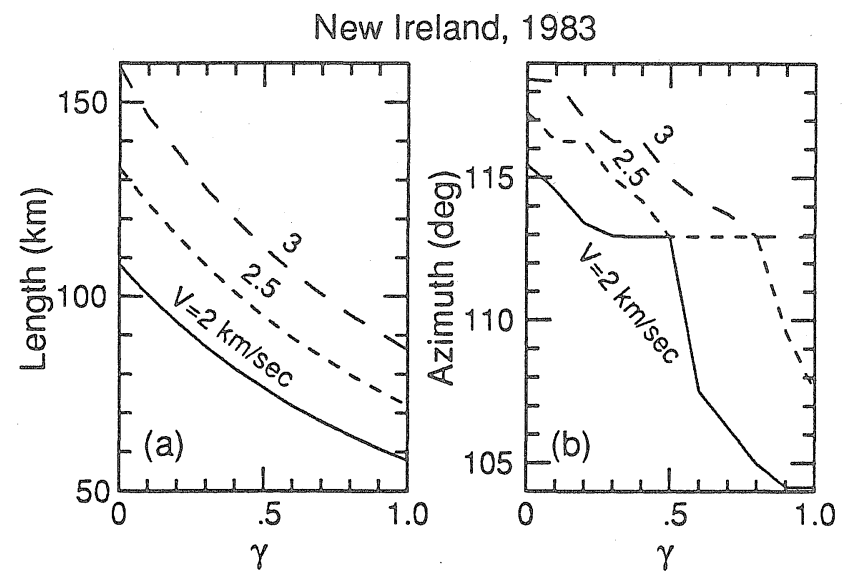

Fig. 17. New Ireland earthquake. The rupture parameters as functions of the ratio $\gamma$ for the rupture velocities of 2 (solid line), 2.5 (dotted line), and 3 (dashed line) $\mathrm{km} / \mathrm{sec}$. The inversion is at the period $256 \mathrm{~s}$. (a) The half rupture length, $\mathrm{L}$. The rupture is assumed to be strictly bilateral $\left(\mathrm{L}_{1}=\mathrm{L}_{2}=\mathrm{L}\right)$ with $\mathrm{L}_{1}$ toward the east. (b) The rupture azimuth. The rupture is assumed to be strictly bilateral with a half length $\mathrm{L}$ of $60 \mathrm{~km}$.

estimate of the total rupture length is about $200 \mathrm{~km}$, which is about twice as long as the aftershock area. If the aftershock area represents the extent of the faulting of the earthquake, Figure $17 \mathrm{a}$ indicates that the rupture of the earthquake has a larger $\gamma$ than usually expected. Assuming a rupture velocity of 2 $\mathrm{km} / \mathrm{s}$ and $\gamma=1$, the estimate of the total rupture length is 120 $\mathrm{km}$ in the azimuth of $104^{\circ}$. Both the rupture time and the rise time for this rupture model are $30 \mathrm{~s}$ long. The long rise time may represent the long duration of hinge faulting.

If we assumed that the rupture was unilateral with a rupture velocity of $2 \mathrm{~km} / \mathrm{s}$ and $\gamma=0.1$, the estimate of total rupture length is $100 \mathrm{~km}$ in the azimuth of $294^{\circ}$. The rupture direction obtained here for a unilateral or a bilateral rupture is parallel to the Solomon trench. The minimum error in inversions using various combinations of rupture lengths suggests marginally that the rupture of the earthquake is perhaps bilateral.

We used the finite-fault model of a bilateral rupture with total rupture length of $120 \mathrm{~km}$ and rupture velocity of $2 \mathrm{~km} / \mathrm{s}$ toward the azimuth of $104^{\circ}$ and $\gamma=1$ to estimate the depth of the earthquake. The centroid depth obtained by the moment tensor inversion and fault inversion with $(\mathrm{K} 70,5.08 \mathrm{M})$ are 77 and $78 \mathrm{~km}$, respectively. Figure $18 \mathrm{a}$ shows the RMS error

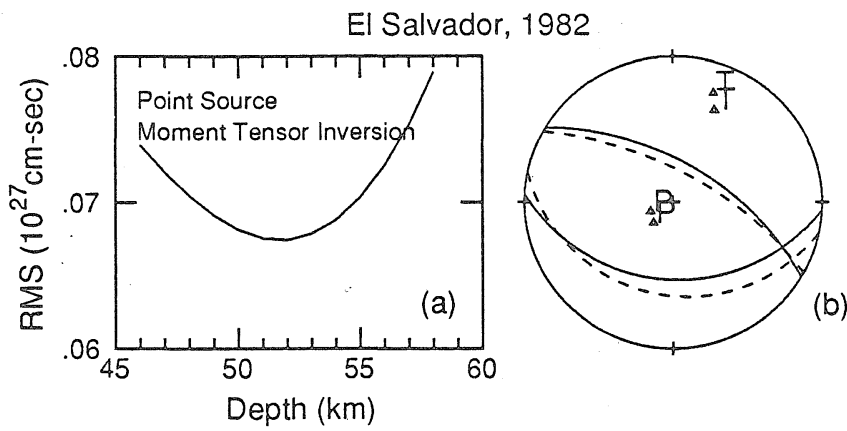

Fig. 16. El Salvador earthquake. (a) Residual versus depth curves by the moment tensor inversion are given for the finite-fault model obtained. (b) The source mechanism of the major double couple listed in Table 5 (solid line) is compared with the best double couple of the Harvard CMT solution (dashed line).

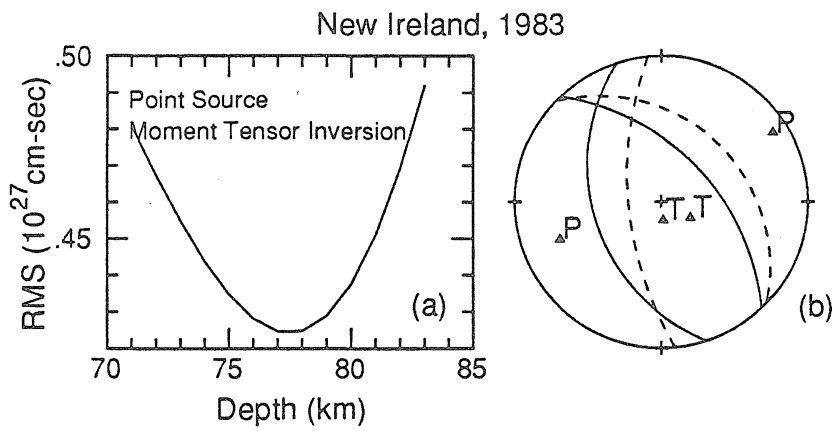

Fig. 18. New Ireland earthquake. (a) Residual versus depth curves by the moment tensor inversion are given for the finite-fault model obtained. (b) The source mechanism of the major double couple listed in Table 5 (solid line) is compared with the best double couple of the Harvard CMT solution (dashed line). 


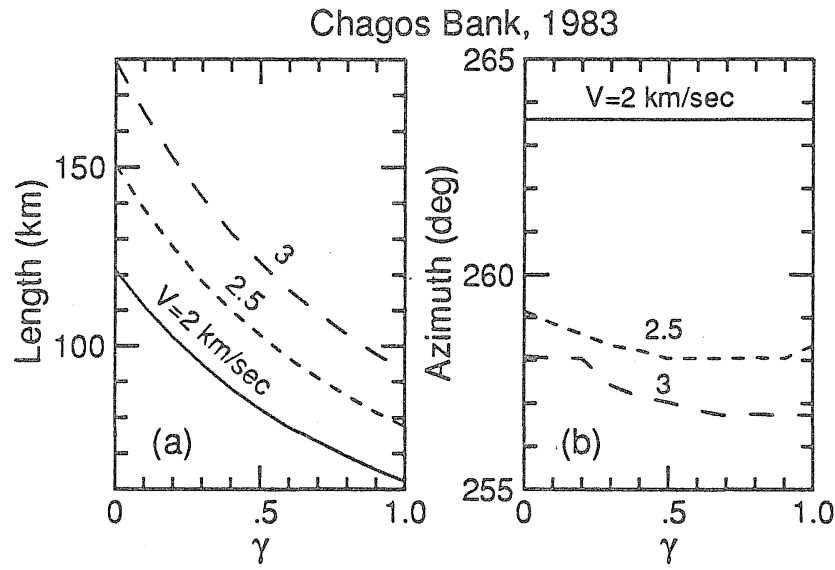

Fig. 19. Chagos Bank earthquake. The rupture parameters as functions of the ratio $\gamma$ for the rupture velocities of 2 (solid line), 2.5 (dotted line), and 3 (dashed line) $\mathrm{km} / \mathrm{sec}$. The inversion is at the period $256 \mathrm{~s}$. (a) The rupture length. The rupture is assumed to be unilateral toward $\mathrm{N} 65^{\circ} \mathrm{W}$. (b) The rupture azimuth. The rupture is assumed to be unilateral with a length of $110 \mathrm{~km}$.

versus trial centroid-depth curve for the moment tensor inversion. The moment tensor solution for the depth of $77 \mathrm{~km}$ is listed in Table 5, which has a major double couple of reverse fault type with a small strike-slip component. Figure $18 \mathrm{~b}$ shows the comparison of the major double couple and the best double couple of the CMT solution. The double couple solution obtained from the fault inversion is listed in Table 6. If we used the unilateral rupture to represent the source finiteness of the earthquake, the depths obtained by the moment tensor or fault inversion are about the same.

Using a point source model with 58 -s duration determined by $\mathbb{Z K}$, we obtained the same centroid depth as that using the finite-fault model.

\subsection{Chagos Bank Earthquake}

This earthquake $\left(M_{s}=7.7\right)$ occurred at the southern end of the Chagos Bank in a young lithosphere of the Indian plate, near the Central Indian ridge and gives evidence of massive internal deformation taking place in the Indian plate [Stein and Okal, 1978; Weissel et al., 1980]. Near-ridge earthquakes occur along all major midocean ridge systems, but the Central Indian Ocean ridge is unusually active; normal fault events occur primarily in the Indian Ocean [Wiens and Stein, 1984; Bergman and Solomon, 1984]. The intense seismicity in the region between the Ninetyeast and Chagos ridges may indicate an early stage of converging plate boundary, which is in N-S compression in the Central Indian Ocean and N-S extension near Chagos [Wiens et al., 1985; Wiens, 1986]. The body waves of the 1983 earthquake recorded at GDSN stations suggest that the earthquake is a nearly pure normal fault event along a fault striking roughly east-west [Wiens and Stein, 1984], a typical mechanism for events near the Chagos Bank [Stein and Okal, 1978; Bergman and Solomon, 1984]. The hypocenter depth reported by the NEIC is $10 \mathrm{~km}$. The CMT solution gives depth $10 \mathrm{~km}$. The centroid depth of the U.S. Geological Survey (USGS) moment tensor solution reported from PDE listings of the NEIC is $36 \mathrm{~km}$. Wiens and Stein [1984] obtained a depth of $16 \mathrm{~km}$ from body wave data.

The aftershocks within one day after the main shock reported by the NEIC are distributed in an area about $110 \mathrm{~km}$ long extending $N 65^{\circ} \mathrm{W}$ from the epicenter of the main event.
The inversions of the spectra for various combinations of rupture lengths and azimuths yield a minimum for a unilateral rupture. This minimum is not significantly smaller than other local minima for different rupture modes. This indicates that the rupture mode cannot be determined well from the inversion. Figures $19 \mathrm{a}$ and $19 \mathrm{~b}$ show the rupture length and rupture azimuth estimated for a unilateral rupture for various $\gamma$ and $V$, respectively. For a rupture velocity of $2 \mathrm{~km} / \mathrm{s}$ and $\gamma=0.1$, the estimates of rupture length and rupture azimuth are $110 \mathrm{~km}$ and $258^{\circ}$, respectively.

Using the finite-fault model obtained, we determined the centroid depth. The model is a unilateral rupture of $110 \mathrm{~km}$ with a rupture velocity of $2 \mathrm{~km} / \mathrm{s}$ in the $S 78^{\circ} \mathrm{W}$ direction and $\gamma=0.1$. The centroid depths obtained by the moment tensor inversion and fault inversion with $(\mathrm{K} 70,5.08 \mathrm{M})$ are both $36 \mathrm{~km}$ (Figure 20a). This is much larger than the CMT depth and the depth reported by the NEIC. Our estimate is consistent with the depth of the USGS moment tensor solution. Later we estimated the uncertainty of the depth estimate of the earthquake and obtained a depth range 16 to $41 \mathrm{~km}$ with $90 \%$ confidence. Since the source finiteness of the earthquake is well constrained by the Rayleigh wave data, and the difference of the estimates of the depth for various earth models is less than $10 \mathrm{~km}$, our result from surface wave data indicates a deeper source than those given by several other investigators.

The moment tensor solution for the centroid depth of $36 \mathrm{~km}$ is listed in Table 5. The scalar moment is $7.7 \times 10^{27} \mathrm{dyn} \mathrm{cm}$. Figure $20 \mathrm{~b}$ compares the mechanisms of the major double couple of the moment tensor solution and the best double couple of the CMT solution. These solutions are in general consistent and indicate a north-south tension in this region.

Using a point source model with 63-s duration determined by $\mathrm{ZK}$, we obtained a centroid depth of $34 \mathrm{~km}$ by the moment tensor inversion and by the fault inversion.

\subsection{Valparaiso, Chile, Earthquake}

This earthquake occurred under the coast of central Chile, where the subduction of the Nazca plate has a smaller dip angle $\left(<30^{\circ}\right)$ than at northern and southern Chile [Barazangi and Isacks, 1976]. The CMT and USGS moment tensor solutions give 41 and $51 \mathrm{~km}$ for the centroid depth, respectively.

In determining the depth of the earthquake, we adapted the finite-fault model obtained by $\mathrm{ZK}$. In this model, the rupture is unilateral, $149 \mathrm{~km}$ long with a rupture velocity of $2.5 \mathrm{~km} / \mathrm{s}$ toward the $S 15^{\circ} \mathrm{W}$ direction and $\gamma=0.1$. The centroid depth is estimated to be $48 \mathrm{~km}$ by the moment tensor inversion with

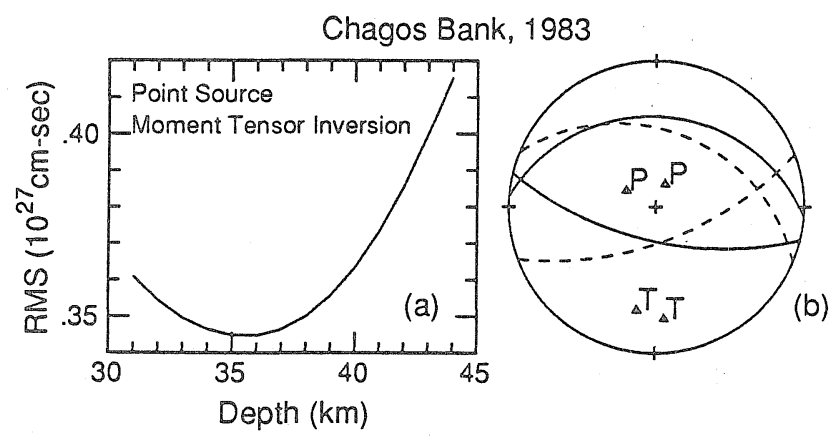

Fig. 20. Chagos Bank earthquake. (a) Residual versus depth curves by the moment tensor inversion are given for the finite-fault model obtained. (b) The source mechanism of the major double couple listed in Table 5 (solid line) is compared with the best double couple of the Harvard CMT solution (dashed line). 
(K70, 5.08M) (Figure 21a). The moment tensor solution obtained for the depth is listed in Table 5. The solution is consistent with the CMT solution. In Figure $21 \mathrm{~b}$ the two nodal planes of the major double couple of the moment tensor are compared with the CMT solution, which has strike $11^{\circ}$, dip $26^{\circ}$, and slip $110^{\circ}$. The depth obtained by the fault inversion is $44 \mathrm{~km}$. The double couple mechanism obtained by the fault inversion at this depth is listed in Table 6.

Most of the recent large earthquakes in central Chile have the typical thrust mechanism of interplate earthquakes with depths from 20 to $70 \mathrm{~km}$ [Malgrange et al., 1981; Malgrange and Madariaga, 1983; Korrat and Madariaga, 1986]. The 1985 earthquake may also be one of these earthquakes near or beneath the interface between the two converging plates representing the underthrusting of the Nazca plate beneath the South America plate. Analysis of geodetic data by Barrientos and Ward [1987] on elevation changes due to deformation associated with the earthquake suggests that most of the fault slip of the earthquake occurred at a depth between 30 and $40 \mathrm{~km}$. The body wave study of Christensen and Ruff [1986] defines a depth distribution with a lower bound of about $40 \mathrm{~km}$ for the earthquake.

Dewey et al. [1985] relocated teleseismically well-recorded earthquakes (magnitude 4.5 or larger) that occurred from 1964 through March 1985, in and near the aftershock zone of the 1985 earthquake. The seismicity near plate-thrust interface in this region clustered into a pair of deep and shallow thrust zones, which are separated by a $20-\mathrm{km}$ region of lower seismicity centered at a depth of about $35 \mathrm{~km}$ in the plane of the interface. Most of the aftershocks of the earthquake (magnitude less than 6.0) were concentrated in the shallow zone; in the deep zone, some aftershocks of magnitude 6.0 or greater occurred during the first day after the main shock, but few shocks of magnitude between 4.5 and 5.9 occurred.

If body waves were radiated mostly from the upper $40-\mathrm{km}$ portion of the fault plane, the centroid depth at $48 \mathrm{~km}$ obtained from our study suggests that rupture extended considerably below the shallow thrust zone and was responsible for radiation of long-period waves. If we assumed that the rupture extended from depths of 40 to $60 \mathrm{~km}$ with a fault width $W=20 / \sin 21^{\circ} \mathrm{km}$ and a fault length $L=149 \mathrm{~km}$, the average displacement would be about $\bar{D}=2.1 \mathrm{~m}$ for a rigidity $\mu=7 \times 10^{11} \mathrm{dyn} / \mathrm{cm}^{2}$. The stress drop was $\Delta \sigma \sim 9$ bars. The seismic slip of the earthquake is much smaller than the cumulative displacement $(7.2 \mathrm{~m})$ since the 1906 earthquake calculated

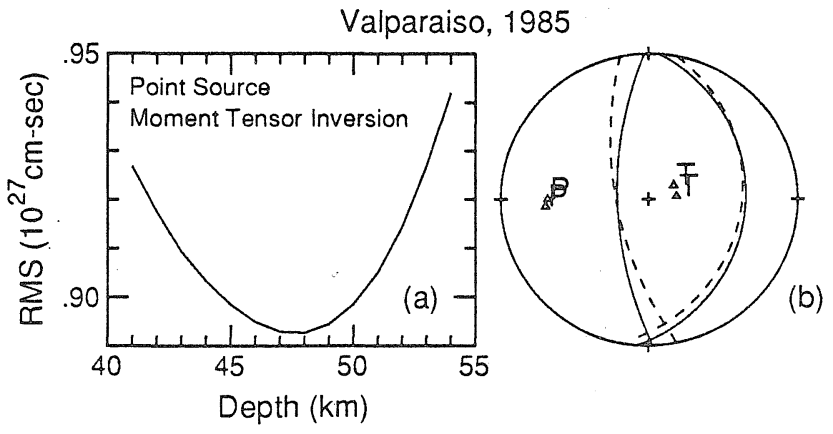

Fig. 21. Valparaiso, Chile, earthquake. (a) Residual versus depth curves by the moment tensor inversion are given for the finite-fault model obtained by Zhang and Kanamori [1988]. (b) The source mechanism of the major double couple listed in Table 5 (solid line) is compared with the best double couple of the Harvard CMT solution (dashed line).

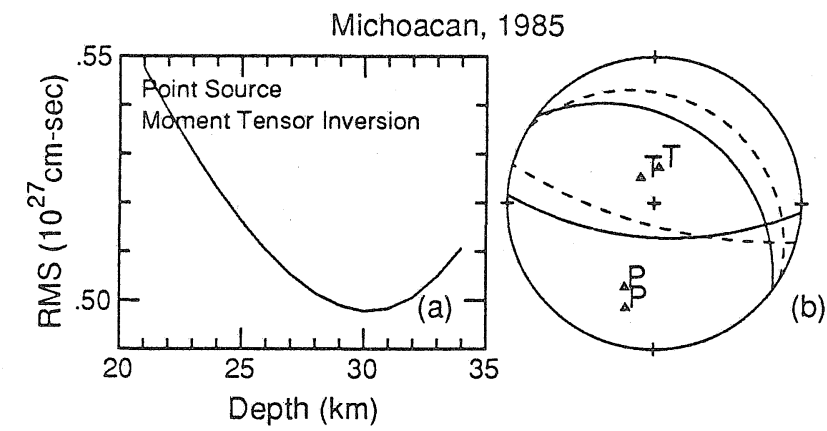

Fig. 22. Michoacan, Mexico, earthquake. (a) Residual versus depth curves by the moment tensor inversion are given for the finite-fault model obtained by Zhang and Kanamori [1988]. (b) The source mechanism of the major double couple listed in Table 5 (solid line) is compared with the best double couple of the Harvard CMT solution (dashed line).

from the Nazca-South America convergence rate of $9 \mathrm{~cm} / \mathrm{yr}$ [Stein et al., 1986].

Using a point source model with 69 -s duration determined by $\mathrm{ZK}$, we obtained a centroid depth of $47 \mathrm{~km}$ by the moment tensor inversion and of $44 \mathrm{~km}$ by the fault inversion with (K70, 5.08M).

\subsection{Michoacan, Mexico, Earthquake}

This earthquake occurred at the northwest portion of the Middle America trench, where the Cocos plate subducts to the northeast under the North America plate. The depth of the earthquake hypocenter reported by the NEIC is $28 \mathrm{~km}$. The CMT depth is $21.3 \mathrm{~km}$.

In determining the depth from Rayleigh wave data, we used the source-finiteness model obtained by $\mathrm{ZK}$, which has rupture length $165 \mathrm{~km}$, rupture velocity $2.5 \mathrm{~km} / \mathrm{s}$ in the azimuth of $123^{\circ}$, and $\gamma=0.1$. Figure $22 \mathrm{a}$ shows the residual versus centroid-depth curve for the moment tensor inversion with $(\mathrm{K} 70,5.08 \mathrm{M})$. The estimate of centroid depth is $30 \mathrm{~km}$. The moment tensor solution for the centroid depth at $30 \mathrm{~km}$ is listed in Table 5, which has a dip angle of $30.8^{\circ}$ for the major double couple of the moment tensor. The results obtained by the fault inversion are similar to those obtained by the moment tenscr inversion. The centroid depth and fault mechanism obtained by the fault inversion are listed in Table 6.

The tsunami generated by the earthquake has 1.4 - $\mathrm{m}$ peak-totrough high at Acapulco, Mexico, about $400 \mathrm{~km}$ southeast of the epicenter, which may suggest that the fault broke the surface. We used the moment tensor inversion with excitation functions for the extended source and found a depth extent of $54 \mathrm{~km}$.

In Figure 22b, the two nodal planes of the major double couple of the moment tensor are compared with the CMT solution. We also determined the depth of the earthquake using other source-finiteness models, which include the models of the source process time and the source directivity with various rupture lengths and rupture velocities. The results remain about the same.

The result obtained for (D-S, R-A) is listed in Table 2. The centroid depth obtained with (D-S, R-A) is approximately the same as that of the CMT solution.

The dip angle obtained from our method is greater than in the $\mathrm{P}$ wave first-motion solution reported by the NEIC and the CMT solution. The discrepancy reflects the difficulty and uncertainty in determining dip angle for shallow earthquakes. 
Using a point source model with 77-s duration determined by $\mathrm{ZK}$ and $(\mathrm{K} 70,5.08 \mathrm{M})$, we obtained the same centroid depth as that using the finite-fault model.

\section{Resolution OF DePTH}

Since the wavelength of Rayleigh waves with a period of $150-300 \mathrm{~s}$ is about $1000 \mathrm{~km}$, there is in general a large uncertainty in the estimate of the depth at which the preferred minimum occurs. A t test can be applied to estimate the uncertainty of the depth estimated from long-period surface waves. A similar use of the $t$ test is given by Huang et al. [1986] to assess the precision of the body wave depths.

The moment tensor or the double couple solution of the best fitting source minimizes the sum of the squared residual,

$$
\rho^{2}=\sum_{i=1}^{5 K} \rho_{i}^{2}
$$

where

$$
\rho_{i}=\Lambda_{i}-\hat{\Lambda}_{i} \quad(i=1, \ldots, 5 K)
$$

Here $\Lambda_{i}$ and $\hat{\Lambda}_{i}$ are the observed and predicted components of vector $\Lambda$ in (5).

The differences of the squared residuals $\rho_{i}^{2}$ at two depths $A$ and $B$

$$
\delta_{i}=\rho_{i A}^{2}-\rho_{i B}^{2} \quad(i=1, \ldots, 5 K)
$$

can be considered samples of a random variable following a normal distribution with mean $\mu$ and standard deviation $\sigma$. In order to assess the statistical significance of the differences, we test the null hypothesis $\mu=0$. We define the statistic

$$
t=\frac{\bar{\delta}}{s / \sqrt{5 K}}
$$

where $\bar{\delta}$ and $S$ are the mean and the square root of the variance of $\delta_{i}(i=1, \ldots, 5 K)$. If

$$
\sum_{i=1}^{5 K} \rho_{i A}^{2}>\sum_{i=1}^{5 K} \rho_{i B}^{2}
$$

and $t$ exceeds a threshold value $t_{\alpha}$ determined by the Student's $t$ distribution for a given significance level $\alpha$, then the alternate hypothesis $\mu>0$ is accepted, which indicates that the solution at depth $B$ is better than at depth $A$ at the given significance level.

For each earthquake, we computed the $t$ statistic for the best fitting depth and nearby depths. We determine the depths at which $t$ exceeds the threshold value $t_{\alpha}$ for a $90 \%$ confidence using a one-sided Student's $t$ test with $5 \mathrm{~K}-1$ degree of freedom. In the inversion, we used the group velocities and $Q$ of D-S and the excitation function of R-A. Table 3 lists the $90 \%$ confidence interval for the depth of each earthquake.

For the New Ireland earthquake, the CMT depth is slightly shallower than the depth range given in Table 3: 72 to $79 \mathrm{~km}$. For the Chagos Bank earthquake, the CMT depth is fixed at 10 $\mathrm{km}$, which is shallower than the depth range obtained here: 16 to $41 \mathrm{~km}$. For other earthquakes, the CMT depths are within the depth range given in Table 3 .

\section{Discussion}

The accuracy of the depth determination depends critically on how accurately we can correct the observed spectra for the source-finiteness effect and propagation effects on both phase and amplitude. Also the choice of excitation functions is required.

For the correction of source-finiteness effect, the method developed by Zhang and Kanamori [1988] is effectively used for very large earthquakes. For the smaller events, the details of the source-finiteness effect cannot be determined. However, since its effect on the depth determination is small, the uncertainty in the source-finiteness model is not a serious problem for these smaller events. We feel that we can correct for the source-finiteness effect with sufficient accuracy for reliable depth determination.

The propagation effects on the phase can be estimated with good accuracy using recently developed laterally heterogeneous earth models such as the model M84C at periods longer than $150 \mathrm{~s}$. At periods shorter than $150 \mathrm{~s}$, presently available models are not adequate.

The propagation effects on the amplitude can be estimated using global average $Q$ models. As Figure 6 shows, the difference in the depth estimates determined for different $Q$ models is small. However, the difference is systematic for different models and is significant for shallow events. Since the model presented by Dziewonski and Steim [1982] is considered a good global average, we prefer the results obtained using this model.

The effect of different earth models used for the computation of excitation functions on the depth determination is less critical compared with the effect of source-finiteness models. However, since most earthquakes studied in this paper occurred in subduction zones, the average ocean model of Regan and Anderson [1984] may be a reasonable choice for the purpose of depth determination. We summarize the results obtained with the combination of the D-S Q model and R-A earth model in Tables 2 and 3 as our preferred solutions.

The depth range listed in Table 3 for each event represents the precision of the depth determination when the earth model is fixed. Figure 6 shows that for a change in $\mathrm{Q}$ of $3 \%$, which is about half of the difference between PREM and D-S, the variation of depth is about $5 \mathrm{~km}$ for an earthquake of depth 30 $\mathrm{km}$ and becomes smaller for deeper earthquakes. The systematic error in the depth determination for each earthquake resulting from uncertainties in the earth models is within the range listed in Table 3.

\section{Conclusions}

We determined the depths and source mechanisms of nine large earthquakes from long-period (150 to 300 s) Rayleigh waves recorded at IDA and GDSN stations. We inverted the data set of complex source spectra for a moment tensor (linear) or a double couple (nonlinear). By solving a least squares problem, we obtained the centroid depth or the extent of the distributed source of each earthquake.

The depths and source mechanisms of large shallow earthquakes determined from long-period Rayleigh waves depend on the models of source finiteness, wave propagation, and excitation. We tested various models of source finiteness, $Q$, group velocity, and excitation. We conclude that the depth estimates obtained using the $Q$ model of Dziewonski and Steim [1982] and the excitation functions computed for the average ocean model of Regan and Anderson [1984] are most reasonable. Dziewonski and Steim's [1982] Q model represents a good global average of $Q$ determined over a period range of the Rayleigh waves used in this study. Since most of the earthquakes 
studied here occurred in subduction zones, Regan and Anderson's [1984] average ocean model is considered most appropriate.

Our depth estimates are in general consistent with Harvard centroid-moment tensor (CMT) solutions. The centroid depths and their $90 \%$ confidence intervals (numbers in parentheses) determined by the Student's $\mathbb{t}$ test are Colombia-Ecuador earthquake (December 12, 1979), $d=11 \mathrm{~km}(9,24 \mathrm{~km})$; Santa Cruz Island earthquake (July 17, 1980), $d=36 \mathrm{~km}(18,46 \mathrm{~km}$ ); Samoa earthquake (September 1, 1981), $d=15 \mathrm{~km}(9,26 \mathrm{~km})$; Playa Azul, Mexico, earthquake (October 25, 1981), $d=41 \mathrm{~km}$ $(28,49 \mathrm{~km})$; El Salvador earthquake (June 19, 1982), $d=49$ $\mathrm{km}(41,55 \mathrm{~km})$; New Ireland earthquake (March 18, 1983), d = $75 \mathrm{~km}(72,79 \mathrm{~km})$; Chagos Bank earthquake (November 30, 1983), d = $31 \mathrm{~km}(16,41 \mathrm{~km})$; Valparaiso, Chile, earthquake (March 3, 1985), d = $44 \mathrm{~km}(15,54 \mathrm{~km})$; Michoacan, Mexico, earthquake (September 19, 1985), $d=24 \mathrm{~km}(12,34 \mathrm{~km}$ ).

\section{APPENDIX}

For Love waves, equations of the inversion for the moment tensor and double couple are described as follows, which are similar to those for Rayleigh waves.

\section{Moment Tensor Inversion From Love Waves}

For the moment tensor inversion, the first step solves the following system:

$$
B D=V
$$

where

$$
B=\left[\begin{array}{cccc}
-\frac{1}{2} \sin 2 \phi_{1} & -\cos 2 \phi_{1} & 0 & 0 \\
0 & 0 & -\sin \phi_{1} & \cos \phi_{1} \\
-\frac{1}{2} \sin 2 \phi_{2} & -\cos 2 \phi_{2} & 0 & 0 \\
0 & 0 & -\sin \phi_{2} & \cos \phi_{2} \\
\cdot & \cdot & \cdot & \cdot \\
\cdot & \cdot & \cdot & \cdot \\
\cdot & \cdot & \cdot & \cdot \\
-\frac{1}{2} \sin 2 \phi_{N} & -\cos 2 \phi_{N} & 0 & 0 \\
0 & 0 & -\sin \phi_{N} & \cos \phi_{N}
\end{array}\right]
$$

and

$$
\begin{aligned}
D=\left[P_{L}^{(1)}(\omega, h)\left(M_{y y}-M_{x x}\right),\right. & P_{L}^{(1)}(\omega, h) M_{x y}, \\
& \left.Q_{L}^{(1)}(\omega, h) M_{x z}, Q_{L}^{(1)}(\omega, h) M_{y z}\right]^{T}
\end{aligned}
$$

and

$$
\begin{aligned}
V=\left[\alpha\left(\omega, h, \phi_{1}\right), \beta\left(\omega, h, \phi_{1}\right),\right. & \cdots, \\
& \left.\alpha\left(\omega, h, \phi_{N}\right), \beta\left(\omega, h, \phi_{N}\right)\right]^{T}
\end{aligned}
$$

where $\mathbb{N}$ is the number of records obtained from stations with azimuths $\phi_{1}, \cdots, \phi_{N}$ from the source, and $\alpha$ and $\beta$ are defined in (3). $B$ is a $2 \mathrm{~N} \times 4$ real matrix, and $V$ is a real vector with dimension $2 \mathrm{~N}$. The system $(\mathrm{A} 1)$ is solved for $D(\omega)$ using the data vector $V(\omega)$ at several frequencies: $\omega_{1}, \omega_{2}, \ldots, \omega_{K}$.

The second step solves the following system:

$$
\Gamma M=\Lambda
$$

for the moment tensor from the vectors $D\left(\omega_{i}\right),(i=1, \ldots, K)$ for given excitation functions, where

$$
\begin{gathered}
\Gamma=\left[\Gamma_{1}, \Gamma_{2}, \ldots, \Gamma_{R}\right]^{T} \\
\Gamma_{i}=\operatorname{diag}\left[P_{L}^{(1)}\left(\omega_{i}, h\right), P_{L}^{(1)}\left(\omega_{i}, h\right),\right. \\
\left.Q_{L}^{(1)}\left(\omega_{i}, h\right), Q_{L}^{(1)}\left(\omega_{i}, h\right)\right] \quad(i=1, \ldots, K) \\
M=\left[\left(M_{y y}-M_{x x}\right), M_{x y}, M_{x z}, M_{y z}\right]^{T}
\end{gathered}
$$

and

$$
\Lambda=\left[D^{T}\left(\omega_{1}\right), D^{T}\left(\omega_{2}\right), \ldots, D^{T}\left(\omega_{K}\right)\right]^{T}
$$

\section{Double Couple Inversion From Love Waves}

For the fault inversion, the system (A1) is solved in the first step for $D(\omega)$ at various frequencies. Here the matrix $B$ remains unchanged, while the vector $D(\omega)$ is replaced by

$$
\begin{aligned}
D= & {\left[\mathbb{P}_{L}^{(1)}(\omega, h) m_{2}, P_{L}^{(1)}(\omega, h) m_{1},\right.} \\
& \left.Q_{L}^{(1)}(\omega, h) m_{5}, Q_{L}^{(1)}(\omega, h) m_{4}\right]^{T}
\end{aligned}
$$

where $m_{i}(i=1, \ldots, 5)$ are defined in the text.

In the second step, a system in the form of (A2) is solved for $M_{o}, \delta, \lambda$, and $\phi_{f}$ using the vector $\Gamma$. Here $\Gamma_{i}(i=1, \ldots, K)$ remain the same as in (A2); while the vector $M$ in the system is replaced by $M=\left(m_{2}, m_{1}, m_{5}, m_{4}\right)$, where $m_{i}(i=1, \ldots, 5)$ are nonlinear functions of $\delta, \lambda$, and $\phi_{f}$.

\section{Moment Tensor and Double Couple Inversion \\ From both Rayleigh and Love Waves}

If both Rayleigh waves and Love waves are used, equations for the first step and the second step are similar to (4), (A1), and (5), (A2), respectively. For the moment tensor inversion, the first step solves the following system:

$$
B D=V
$$

where

$$
\begin{aligned}
& B=\left[B_{1}^{T}, B_{2}^{T}, \ldots, B_{N}^{T}\right]^{T} \\
& \mathbb{B}_{i}=\left[B_{i R}^{T}, B_{i L}^{T}\right]^{T} \quad(i=1, \ldots, N) \\
& B_{i R}=\left[\begin{array}{ccccccccc}
-\sin 2 \phi_{i} & \frac{1}{2} \cos 2 \phi_{i} & -\frac{1}{2} & 0 & 0 & 0 & 0 & 0 & 0 \\
0 & 0 & 0 & \sin \phi_{i} & \cos \phi_{i} & 0 & 0 & 0 & 0
\end{array}\right] \\
& B_{i L}=\left[\begin{array}{ccccccccc}
0 & 0 & 0 & 0 & 0 & -\frac{1}{2} \sin 2 \phi_{i} & -\cos 2 \phi_{i} & 0 & 0 \\
0 & 0 & 0 & 0 & 0 & 0 & 0 & -\sin \phi_{i} & \cos \phi_{i}
\end{array}\right] \\
& D=\left[P_{R}^{(1)}(\omega, h) M_{x y}, P_{R}^{(1)}(\omega, h)\left(M_{y y}-M_{x x}\right),\right. \\
& S_{R}^{(1)}(\omega, h)\left(M_{y y}+M_{x x}\right), Q_{R}^{(1)}(\omega, h) M_{y z}, \\
& Q_{R}^{(1)}(\omega, h) M_{x z}, P_{L}^{(1)}(\omega, h)\left(M_{y y}-M_{x x}\right), \\
& \left.\mathbb{P}_{L}^{(1)}(\omega, h) M_{z y}, Q_{L}^{(1)}(\omega, h) M_{z z}, Q_{L}^{(1)}(\omega, h) M_{y z}\right]^{T}
\end{aligned}
$$


and

$$
\begin{gathered}
V=\left[\alpha_{R}\left(\omega, h, \phi_{1}\right), \beta_{R}\left(\omega, h, \phi_{1}\right),\right. \\
\alpha_{L}\left(\omega, h, \phi_{1}\right), \beta_{L}\left(\omega, h, \phi_{1}\right), \\
\cdots, \\
\alpha_{R}\left(\omega, h, \phi_{N}\right), \beta_{R}\left(\omega, h, \phi_{N}\right), \\
\left.\alpha_{L}\left(\omega, h, \phi_{N}\right), \beta_{L}\left(\omega, h, \phi_{N}\right)\right]^{T}
\end{gathered}
$$

If only Rayleigh waves (or Love waves) are used at a station with the azimuth $\phi_{i}$, then only $\alpha_{R}\left(\omega, h, \phi_{i}\right)$ and $\beta_{R}\left(\omega, h, \phi_{i}\right)$ (or $\alpha_{L}\left(\omega, h, \phi_{i}\right)$ and $\beta_{L}\left(\omega, h, \phi_{i}\right)$ ) are included in the data vector $\mathrm{V}$, and $B_{i R}$ (or $B_{i L}$ ) is used for $B_{i}$. The system (A3) is solved for $D(\omega)$ at several frequencies: $\omega_{1}, \omega_{2}, \ldots, \omega_{K}$.

The second step solves the following system:

$$
\Gamma M=\Lambda
$$

where

$$
\begin{gathered}
M=\left[M_{x y},\left(M_{y y}-M_{x x}\right),\left(M_{y y}+M_{x x}\right), M_{y z}, M_{x z}\right]^{T} \\
\Lambda=\left[D^{T}\left(\omega_{1}\right), D^{T}\left(\omega_{2}\right), \ldots, D^{T}\left(\omega_{K}\right)\right]^{T}
\end{gathered}
$$

and

$$
\begin{gathered}
\Gamma=\left[\Gamma_{1 R}, \Gamma_{1 L}^{T}, \Gamma_{2 R}, \Gamma_{2 L}^{T}, \cdots, \Gamma_{K R}, \Gamma_{K L}{ }^{T}\right]^{T} \\
\Gamma_{i R}=\operatorname{diag}\left[P_{R}^{(1)}\left(\omega_{i}, h\right), P_{R}^{(1)}\left(\omega_{i}, h\right), S_{R}^{(1)}\left(\omega_{i}, h\right),\right. \\
\left.\quad Q_{R}^{(1)}\left(\omega_{i}, h\right), Q_{R}^{(1)}\left(\omega_{i}, h\right)\right](i=1, \ldots, K) \\
\Gamma_{i L}=\left(\Gamma_{i L}^{j l}\right) \quad(i=1, \ldots, K ; j=1, \ldots, 4 ; l=1, \ldots, 5)
\end{gathered}
$$

Here the only nonzero components of $\Gamma_{i L}{ }^{j l}$ are $\Gamma_{i L}{ }^{21}=\Gamma_{i L}{ }^{12}=\mathbb{P}_{L}^{(1)}\left(\omega_{i}, h\right)$ and $\Gamma_{i L}{ }^{35}=\Gamma_{i L}{ }^{44}=Q_{L}^{(1)}\left(\omega_{i}, h\right)$.

For the fault inversion, the first step inversion solves the same system as (A3). In the second step, the equation (A4) is solved for the scalar moment and fault parameters, with the moment tensor components replaced by the nonlinear functions $m_{i}(\mathrm{i}=1, \ldots 5)$ defined in the text.

Acknowledgments. We thank J. H. Woodhouse and A. M. Dziewonski for making available to us coefficients of spherical harmonics for the model M84. The IDA data used in this study were made available by courtesy of the IDA project team at the Institute of Geophysics and Planetary Physics, University of California, San Diego. This work was supported by NSF grant EAR-86-07694. Division of Geological and Planetary Sciences, California Institute of Technology, Pasadena, contribution 4513.

\section{REFERENCES}

Aki, K., The use of Love waves for the study of earthquake mechanism, J. Geophys. Res., 65, 323-331, 1960a.

Aki, K., Study of earthquake mechanism by a method of phase equalization applied to Rayleigh and Love waves, J. Geophys. Res., 65, 729-740, $1960 b$.

Anderson, D. L., and J. W. Given, Absorption band Q model for the Earth, J. Geophys. Res., 87, 3893-3904, 1982.

Anderson, D. L., and R. S. Hart, Attenuation models of the earth, Phys. Earth Planet. Inter., 16, 289-306, 1978a.

Anderson, D. L., and R. S. Hart, Q of the earth, J. Geophys. Res., 83, 5869-5882, $1978 \mathrm{~b}$.

Astiz, L., H. Kanamori, and H. K. Eissler, Source characteristics of earthquakes in the Michoacan seismic gap in Mexico, Bull. Seismol. Soc. Am., 77, 1326-1346, 1987.
Backus, G. E., and M. Mulcahy, Moment tensors and other phenomenological descriptions of seismic sources, I, Continuous displacements, Geophys. J. R. Astron. Soc., 46, 341-361, 1976.

Barazangi, M., and B. L. Isacks, Spatial distribution of earthquakes and subduction of the Nazca plate beneath South America, Geology, 4, 686-692, 1976.

Barrientos, S. E., and S. N. Ward, Slip distribution of the 1985 Central Chile earthquake from geodetic observations (abstract), Seismol. Res. Lett., 58, 8, 1987.

Ben-Menahem, A., Radiation of seismic surface waves from finite moving sources, Bull. Seismol. Soc. Am., 51, 401-435, 1961.

Ben-Menahem, A., S. W. Smith, and T. L. Teng, A procedure for source studies from spectra of long-period seismic body waves, Bull. Seismol. Soc. Am., 55, 203-235, 1965.

Bergman, E. A., and S. C. Solomon, Source mechanisms of earthquakes near midocean ridges from body waveform inversion: Implications for the early evolution of oceanic lithosphere, J. Geophys. Res., 89, 11,415-11,441, 1984.

Chael, E., and D. L. Anderson, Global Q estimates from antipodal Rayleigh waves, J. Geophys. Res., 87, 2840-2850, 1982.

Chase, C. G., Tectonic history of the Fiju plateau, Bull. Seismol. Soc. Am., 82, 3087, 1971.

Christensen, D. H., and L. J. Ruff, Rupture process of the March 3, 1985 Chilean earthquake, Geophys. Res. Lett., 13, 721-724, 1986.

Dewey, J. W., G. L. Choy, and S. P. Nishenko, Asperities and paired thrust zones in the focal region of the Chilean earthquake of March 3, 1985 (abstract), Eos Trans. AGU, 66, 950, 1985.

Dziewonski, A. M., and D. L. Anderson, Preliminary reference Earth model, Phys. Earth Planet. Inter., 25, 297-356, 1981.

Dziewonski, A. M., and J. M. Steim, Dispersion and attenuation of mantle waves through waveform inversion, Geophys. J. R. Astron. Soc., 70, 503-527, 1982.

Dziewonski, A. M., and J. H. Woodhouse, An experiment in systematic study of global seismicity: Centroid-moment tensor solutions for 201 moderate and large earthquakes of 1981, J. Geophys. Res., 88, 3247 $3271,1983$.

Dziewonski, A. M., T.-A. Chou, and J. H. Woodhouse, Determination of earthquake source parameters from waveform data for studies of global and regional seismicity, J. Geophys. Res., 86, 2825-2852, 1981.

Fukao, Y., and M. Kobayashi, Phase and group velocities and Q of mantle Love and Rayleigh waves of the first two modes and their azimuthal dependences for the 1963 Kurile Islands earthquake, Phys. Earth Planet. Inter., 32, 4-35, 1983.

Giardini, D., A. M. Dziewonski, and J. H. Woodhouse, Centroidmoment tensor solutions for 113 large earthquakes in 1977-1980, Phys. Earth Planet. Inter., 40, 259-272, 1985.

Gilber, F., and A. M. Dziewonski, An application of normal mode theory to the retrieval of structure parameters and source mechanisms from seismic spectra, Philos. Trans. R. Soc. London, Ser. A, 278, $187-269,1975$.

Havskov, J., S. K. Singh, E. Nava, T. Dominguez, and M. Rodriguez, Playa Azul, Michoacan, Mexico, earthquakes of 25 October, 1981 $\left(M_{S}=7.3\right)$, Bull. Seismol. Soc. Am., 73, 449-458, 1983.

Herd, D. G., T. L. Youd, H. Meyer, J. L. Arango, C. W. J. Person, and C. Mendoza, The great Tumaco, Colombia earthquake of 12 December 1979, Science, 211, 441-445, 1981.

Isacks, B. L., L. R. Sykes, and J. Oliver, Focal mechanism of deep and shallow earthquakes in the Tonga-Kermadec region and the tectonics of island arcs, Geol. Soc. Am. Bull., 80, 1443-1470, 1969.

Johnson, T., and P. Molnar, Focal mechanism and plate tectonics of the southwest Pacific, J. Geophys. Res., 77, 5000-5032, 1972.

Kanamori, H., Velocity and Q of mantle waves, Phys. Earth Planet. Inter., 2, 259-275, 1970.

Kanamori, H., and J. W. Given, Use of long-period surface waves for rapid determination of earthquake-source parameters, Phys. Earth Plonet. Inter., 27, 8-31, 1981.

Kanamori, H., and J. W. Given, Use of long-period surface waves for rapid determination of earthquake-source parameters, 2, Preliminary determination of source mechanisms of large earthquakes $\left(M_{s} \geq 6.5\right)$ in 1980, Phys. Earth Planet. Inter., 30, 260-268, 1982.

Kanamori, H., and G. S. Stewart, Mode of the strain release along the Gibbs fracture zone, Mid-Atlantic ridge, Phys. Earth Planet. Inter., $11,312-332,1976$.

Korrat, I., and R. Madariaga, Rupture of the Valparaiso (Chile) gap from 1971 to 1985, in Earthquake Source Mechanics, pp. 247-258, 
edited by S. Das, J. Boatwright, and C. 11. Scholz, AGU, Washington, D. C., 1986.

Lay, T., and H. Kanamori, Earthquake doublets in the Solomon Islands, Phys. Earth Planet. Inter., 21, 283-304, 1980.

Le Pichon, X., Sea-floor spreading and continental drift, J. Geophys. Res., 73, 3661-3697, 1968.

Malgrange, M., and R. Madariaga, Complex distribution of large thrust and normal fault earthquakes in the Chilean subduction zone, Geophys. J. R. Astron. Soc., 73, 489-506, 1983.

Malgrange, M., A. Deschamps, and R. Madariaga, Thrust and extensional faulting under the Chilean coast, 1965, 1971 Aconcagua earthquakes, Geophys. J. R. Astron. Soc., 66, 313-331, 1981.

Mendoza, C., and J. W. Dewey, Seismicity associated with the great Colombia-Ecuador earthquakes of 1942, 1958, and 1979: Implications for barrier models of earthquake rupture, Bull. Seismol. Soc. Am., 74, 577-593, 1984.

Mills, J. M., Great-circle Rayleigh wave attenuation and group velocity, IV, Regionalization and pure-path models for shear velocity and attenuation, Phys. Earth Planet. Inter., 17, 323-352, 1978.

Mills, J. M., and A. L. Hales, Great-circle Rayleigh wave attenuation and group velocity, I, Observations for periods between 150 and 600 seconds for seven great-circle paths, Phys. Earth Planet. Inter., 14, 109-119, 1977.

Mills, J. M., and A. L. Hales, Great-circle Rayleigh wave attenuation and group velocity, II, Observations for periods between 50 and 200 seconds for nine great-circle paths and global averages for periods of 50 to 600 seconds, Phys. Earth Planet. Inter., 17, 209-231, 1978.

Molnar, P., and L. R. Sykes, Plate tectonics in the Hispaniola area: Discussion, Geol. Soc. Am. Bull., 82, 1123, 1971.

Nakanishi, I., Phase velocity and Q of mantle Rayleigh waves, Geophys. J. R. Astron. Soc., 58, 35-59, 1979.

Nakanishi, I., and D. L. Anderson, Measurements of mantle wave velocities and inversion for lateral heterogeneity and anisotropy, I, Analysis of great circle phase velocities, J. Geophys. Res., 88, 10,267-10,283, 1983.

Nakanishi, I., and D. L. Anderson, Measurements of mantle wave velocities and inversion for lateral heterogeneity and anisotropy, II, Analysis by the single-station method, Geophys. J. R. Astron. Soc., $78,573-617,1984$.

Nakanishi, I., and H. Kanamori, Source mechanisms of twenty-six large, shallow earthquakes $\left(M_{s} \geq 6.5\right)$ during 1980 from P-wave first motion and long-period Rayleigh wave data, Bull. Seismol. Soc. Am., 74, 805-818, 1984.

Press, F., Earth models consistent with geophysical data, Phys. Earth Planet. Inter., 3, 3-22, 1970.

Regan, J., and D. L. Anderson, Anisotropic models of the upper mantle, Phys. Earth Planet. Inter., 35, 227-263, 1984.

Romanowicz, B. A., and P. Guillemant, An experiment in the retrieval of depth and source mechanism of large earthquakes using very long-period Rayleigh wave data, Bull. Seismol. Soc. Am., 74, 417$437,1984$.
Romanowicz, B. A., and T. Monfret, Source process times and depth of large earthquakes by moment tensor inversion of mantle wave data and the effect of lateral heterogeneity. Ann. Geophys., 4B, (3), 271283, 1986.

Silver, P. G., and T. H. Jordan, Total moment spectra of fourteen large earhhquakes, J. Geophys. Res., 88, 3273-3293, 1983.

Stein, S., and E. A. Okal, Seismicity and tectonics of the Ninetyeast Ridge area: Evidence for internal deformation of the Indian Plate, J. Geophys. Res., 83, 2233-2246, 1978.

Stein, S., J. F. Engeln, C. DeMets, R. G. Gordon, D. Woods, P. Lundgren, D. Argus, C. Stein, and D. A. Wiens, The Nazca-South America convergence rate and the recurrence of the great 1960 Chilean earthquake, Geophys. Res. Lett., 13, 713-716, 1986.

Tanimoto, T., The Backus-Gilbert approach to the three-dimensional structure in the upper mantle, I, Lateral variation of surface wave phase velocity with its error and resolution, Geophys. J. R. Astron. Soc., 82, 105-123, 1985.

Tanimoto, T., The Backus-Gilbert approach to the three-dimensional structure in the upper mantle, II, SH and SV velocity, Geophys. J. R. Astron. Soc., 84, 49-69, 1986.

UNAM Seismology Group, The September 19, 1985, Michoacan earthquake: Aftershock distribution and history of rupture, Geophys. Res. Lett., 13, 573-576, 1986.

Weissel, J. K., R. N. Anderson, and C. A. Geller, Deformation of the Indo-Australian plate, Nature, 287, 284-291, 1980.

Wiens, D. A., Historical seismicity near Chagos: A complex deformation zone in the equatotial Indian Ocean, Earth Planet. Sci. Lett., 76, 350-360, 1986.

Wiens, D. A., and S. Stein, Age dependence of oceanic intraplate seismicity and implications for lithospheric evolution, J. Geophys. Res., 88, 6455-6468, 1983.

Wiens, D. A., and S. Stein, Intraplate seismicity and stresses in young oceanic lithosphere, J. Geophys. Res., 89, 11,442-11,464, 1984.

Wiens, D. A., C. DeMets, R. G. Gordon, S. Stein, D. Argus, J. F. Engeln, P. Lundgren, D. Quible, C. Stein, S. Weinstein, and D. F. Woods, A diffuse plate boundary model for Indian Ocean tectonics, Geophys. Res., Lett., 12, 429-432, 1985.

Woodhouse, J. H., and A. M. Dziewonski, Mapping the upper mantle: Three-dimensional modeling of Earth structure by inversion of seismic waveforms, J. Geophys. Res., 89, 5953-5986, 1984.

Zhang, J., and H. Kanamori, Source finiteness of large earhquakes measured from long-period Rayleigh waves, Phys. Earth Planet. Inter., in press, 1988.

H. Kanamori and J. Zhang, Seismological Laboratory, Califomia Institute of Technology, Pasadena, CA 91125.

(Received August 11, 1987; revised January 20, 1988; accepted February 8, 1988.) 